\title{
Open-ocean orientation and return migration routes of chum salmon based on temperature data from data storage tags
}

\author{
Kevin D. Friedland ${ }^{1, *}$, Robert V. Walker ${ }^{2}$, Nancy D. Davis ${ }^{2}$, Katherine W. Myers ${ }^{2}$, \\ George W. Boehlert ${ }^{3}$, Shigehiko Urawa ${ }^{4}$, Yasuhiro Ueno ${ }^{5}$ \\ ${ }^{1}$ UMass/NOAA CMER Program, Blaisdell House, University of Massachusetts, Amherst, Massachusetts 01003, USA \\ ${ }^{2}$ University of Washington, School of Aquatic and Fishery Sciences, Box 355020, Seattle, \\ Washington 98195-5020, USA \\ ${ }^{3}$ National Marine Fisheries Service, Southwest Fisheries Science Center, Pacific Fisheries Environmental Laboratory, \\ Pacific Grove, California 93950, USA \\ ${ }^{4}$ National Salmon Resources Center, Sapporo 062-0922, Japan \\ ${ }^{5}$ Fisheries Agency of Japan, Tohoku National Fisheries Institute, Hachinohe Branch, Hachinohe 031-0841, Japan
}

\begin{abstract}
Temperature data storage tags were applied to maturing chum salmon Oncorhynchus keta in the Bering Sea during summer 1998, 5 of which were recovered in the coastal waters around Japan. These tags recorded water temperatures experienced by the fish for periods of 62 to $118 \mathrm{~d}$ at resolutions of 15 to $30 \mathrm{~min}$. We considered fine-scale aspects of the data by analyzing diel temperature patterns in regard to the migration behavior and orientation of the fish. During the night, temperatures experienced by the fish changed little, and were among the highest temperatures experienced whereas daytime temperatures often showed dramatic changes as the fish changed depth. We analyzed a time series of temperature differences between sunrise and sunset as an indication of progress made by the fish against horizontal thermal gradients, which was assumed to represent changes in latitudinal position. Daytime differences were positive when the fish were migrating to warmer waters, whereas night-time differences were zero or slightly negative. This suggests that the fish made more progress migrating during the day than at night. We also considered large-scale aspects by examining oceanographic data in relation to the temperatures recorded by the tags. Analysis of possible migration routes based on large-scale patterns of sea surface temperature distributions suggests that zonal (east-west) routes are preferred. These data support the hypothesis that chum salmon utilize orientation cues associated with the sun during open ocean migration. However, whether salmon also utilize additional orientation or navigation mechanisms remains to be determined.
\end{abstract}

KEY WORDS: Chum salmon · Data storage tag $\cdot$ Orientation $\cdot$ Migration

\section{INTRODUCTION}

Anadromous salmonids undertake transoceanic feeding migrations before maturing and homing to their natal rivers to spawn. The ability to traverse a

*E-mail: friedlandk@forwild.umass.edu number of oceanic provinces has provided salmon with a survival advantage over other fish species by enabling them to utilize seasonal production in subarctic regions, often with little interspecific competition. The essence of the anadromous life cyclespawning and rearing of juveniles in freshwater - also provides a survival advantage by releasing both spawners and juveniles from predation pressure in the 
marine environment. In order to accrue these and other benefits, salmon must be able to migrate over vast distances to return to their home rivers. When adult and post-juvenile salmonids are close to land, scientists have been able to study migration. Salmonids imprint and follow olfactory cues to their natal rivers, thus allowing populations to form and be conserved (Dittman et al. 1996). Vertical movements in the water column and orientation with regard to coastal oceanographic features are well-known for some species (Quinn et al. 1989, Thomson et al. 1992, Thomson et al. 1994). Tagging experiments have provided some insight on the precision of open-ocean migration and the ensuing search patterns used by maturing fish at the coast (Royce et al. 1968, Hansen et al. 1993). However, movements in the open ocean, especially over great distances, are still poorly understood.

Scientists have considered open-ocean orientation of salmon from a number of different perspectives. An interesting starting point is the notion that observed large-scale salmonid movements are purely advective, and movements by the fish are essentially random. The debate was started by models suggesting that in order to home with the precision suggested by field data, little active orientation is needed (Saila et al. 1963, Jamon 1990). Although the case for some sort of orientation or navigation is supported by a number of analyses (Royce et al. 1968, Quinn et al. 1984, Hiramatsu et al. 1989, Quinn 1991), feasible results can still be obtained from models using little orientation. We must not overstate the precision of salmonid migration and should remember that the notion of random movement originates from the same data that support directed migration.

Directed migration in animals can be achieved by either navigation or orientation. Navigation is the purposeful movement of an animal based on a sense of location in respect to a migrational goal. Orientation is the ability of an animal to maintain a heading without the benefit of local landmarks or information associated with the migrational goal. Orientation and navigation often use different sensory modalities and populations may have local adaptations for orientation versus navigation that may be more or less robust to environmental variability. The case for navigation versus orientation in salmonids has been supported by observations of migration and studies of anatomy and physiology. Sockeye salmon fry appear to migrate in response to magnetic and celestial cues (Quinn 1980) and the same traits appear to carry forward to the smolt stage (Quinn et al. 1982). Trout appear to have a magnetic sense, as demonstrated in the laboratory by responsive behaviors modified with magnetic fields (Walker et al. 1997). Furthermore, they can detect spatially distinct magnetic stimuli (Haugh et al. 1998).
The morphology and innervation of biogenic magnetite in trout is consistent with the use of these structures to detect magnetic intensity (Diebel et al. 2000), and the presence of magnetite crystals in a range of salmonids would suggest that this is a family-wide trait (Walker et al. 1988, Moore et al. 1990, Ogura et al. 1992). The ability to detect and differentiate magnetic and celestial cues has also been reported for turtles (Lohmann et al. 1998) and birds (Berthold et al. 1992, Wiltschko et al. 1996). If compass navigation is indeed being used, our expectation would be that migrations at sea follow specific courses and that landfall is at specific destinations. However, existing data lack verification in the field, and so do not provide a comprehensive case for navigation.

The case for orientation is supported by similar evidence. Orientation to the direction of light (Hawryshyn et al. 1990) and adaptation in organs such as the pineal gland (Nordtug et al. 1994) would suggest that solar orientation is the responsible mechanism. Open-ocean salmonid migration guided by solar orientation would not be expected to be precise. However, in the context of landfall patterns, it may be precise enough (Dat et al. 1995). In fact, solar orientation has been proposed as the principal guiding mechanism for salmon migration (Hasler 1971), supported by experimental evidence from pink salmon retained in sea cage labyrinths (Stepanov et al. 1979) and also from coastal tracking of steelhead salmon (Ruggerone et al. 1990). But, as with hypotheses based upon directed navigation, the dearth of field observations limits our ability to resolve which combination of sensory mechanisms and migration strategies are responsible.

For this paper we analyzed the temperature recordings from data storage tags fitted to chum salmon Oncorhynchus keta, during their homing migration from the Bering Sea to the Japanese coast. Our goal was to evaluate the temperature change experienced by the salmon with particular regard to diel variation related to migrational progress. In addition, we examined the relationship between putative movement patterns of these fish and temperature patterns in the Northwest Pacific, thus considering likely migration routes. In so doing, we hope to contribute to our understanding of the factors controlling open-ocean migrations of salmonids in general.

\section{MATERIALS AND METHODS}

Data storage tags. Kiwi Ready Logger RL-05T tags (Conservation Devices, Inc., Belmont, MA), embedded in environmentally-resistant clear urethane and with a return address label, were attached to chum salmon captured in the Bering Sea, following techniques 
described in Walker et al. (2000). The tags weigh $\sim 9.5 \mathrm{~g}$ (<3 g in water), with dimensions $40 \times 23 \times 8 \mathrm{~mm}$, and have 1 attachment hole at each end of the long axis. They are capable of measuring temperature over the range -5 to $30^{\circ} \mathrm{C}$ and are accurate to within $0.2^{\circ} \mathrm{C}$, functional to depths in excess of $1000 \mathrm{~m}$, and have an endurance (i.e. battery life) of over $3 \mathrm{yr}$. The clock was periodically calibrated using a quartz crystal. This extended the battery life but resulted in a positive drift of $\sim 10 \mathrm{~s} \mathrm{~d}^{-1}$, which would have resulted in an error of $\sim 10 \mathrm{~min}$ at the end of our experimental period. Considering that this error is less than our observational resolution of $30 \mathrm{~min}$, we decided not to apply any corrections. Each tag had sufficient memory to hold 8192 observations. This memory was initially filled at a rate of 1 observation per $14.0625 \mathrm{~s}$, but once the memory was full, half the data collected were released (i.e. every 2 nd value) and the new data were collected at half the previous sampling rate (i.e. every $28.125 \mathrm{~s}$ ), thereby automatically optimizing the temporal resolution for the total time the tag was deployed. This process was repeated each time the memory filled. Data collection is continuous from the time of manufacture, and was reinitiated to the shortest sampling interval shortly before tag application, by activating a magnetic reed switch. On recovery, data were downloaded to a computer through the use of infrared signals from a light-emitting diode in the tag. Tags were calibrated at the time of manufacture and tested again after recovery.

Tags were attached just anterior to the dorsal fin, using 2 nickel pins $76 \mathrm{~mm}$ in length. The pins were inserted through $6 \mathrm{~mm}$ diameter plastic disks (i.e. washers), then through the 2 holes in the tag, and then through the dorsal musculature of the fish. On the other side of the fish, the pins were passed through $20 \mathrm{~mm}$ or $16 \mathrm{~mm}$ diameter red and white Petersen disks, and the ends were twisted into knots lying flush against the disks.

A total of 55 salmonids were tagged, including 24 chum salmon resulting in the 5 recoveries described in this paper. In order to maximize return rate, only maturing fish, likely to be intercepted by coastal or freshwater fisheries were tagged. Likelihood of capture was estimated from what is known about the highseas distribution of stocks, as determined from previous tagging experiments, and the expected activity of coastal fisheries for those stocks.

Difference analysis. The progress of migration against thermal gradients was assessed by computing 'dusk to dawn' and 'dawn to dusk' temperature differences. Prior to processing the data, day and night codes were calculated and assigned to each temperature observation, assuming a straight-line course between release and recovery sites and dividing the migration period into 4 to 7 time intervals. We then used 2 methods for calculating temperature differences. For the first, computational approach, we developed software that identified sunrise and sunset based on our day/night coding and then computed a dawn and dusk temperature by averaging the first 5 and last 5 night-time temperature observations respectively. Differences between dawn and dusk temperatures were then calculated. For the second, observational approach, we selected dawn and dusk temperatures based on the highest temperature at the end and at the beginning of the night, respectively. The observational approach was applied to the periods during each migration when maximum temperatures began to exceed the local temperatures at the release sites and it was assumed the fish were migrating across thermal gradients (Table 1).

Sea surface temperature. A combination of satellitederived and in situ sea surface temperature (SST) data were obtained for comparison with the temperatures recorded from the tagged salmon. Isotherms for weekly means of daily maximum night-time tag temperatures were plotted, using the optimum interpolation (OI) SST dataset (Reynolds \& Smith 1994). The OI SST data are produced weekly on a $1^{\circ} \times 1^{\circ}$ grid, and use both in situ and satellite SST to determine the fields (Reynolds 1988, Reynolds \& Marsico 1993). A higher $(18 \mathrm{~km})$ resolution satellite-derived SST dataset (NOAA/NASA AVHRR Ocean Pathfinder, Smith et al. 1996) was used to evaluate the low temperature recordings made by the tags during specific weeks in late August and early September 1998. We inspected the distribution of actual versus estimated pixels from the AVHRR data and decided that key regions, such as the Sea of Okhotsk and the area around the Kuril Islands, between Hokkaido and the Kamchatka Peninsula (Fig. 1), were being heavily influenced by the climatology used for estimated pixels. We investigated 2 datasets of in situ observations. The first dataset comprised SST measurements collected as a precursor to the Comprehensive Oceanographic and Atmospheric Dataset (Woodruff et al. 1998). These data were summarized for the region 40 to $50^{\circ} \mathrm{N}$ and 150 to $160^{\circ} \mathrm{E}$

Table 1. Migration periods used for calculation of observational differences

\begin{tabular}{|lcc|}
\hline $\begin{array}{l}\text { Tag } \\
\text { no. }\end{array}$ & Begin & End \\
\hline 255 & 18 Jul 98 & 17 Aug 98 \\
259 & 18 Jul 98 & 17 Aug 98 \\
271 & 07 Jul 98 & 24 Aug 98 \\
274 & 01 Aug 98 & 17 Aug 98 \\
299 & 08 Aug 98 & 07 Sep 98 \\
\hline
\end{tabular}




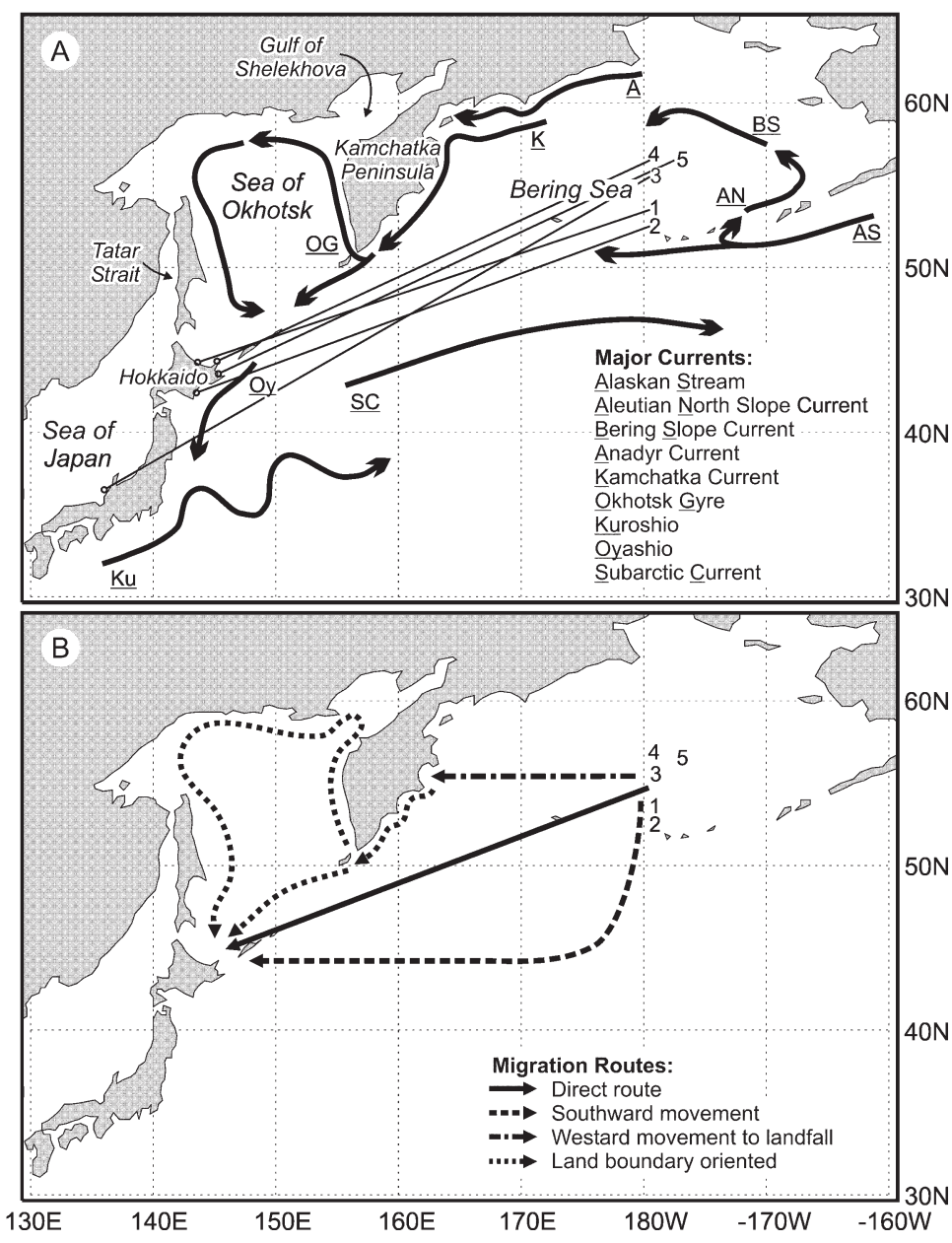

Fig. 1. NW Pacific Ocean (A) release locations and major current systems in the area (B) suggested migration routes during August and September 1998. The second dataset examined was a multi-decadal climatology from the World Ocean Data Base (Levitus et al. 1998), which was used to determine long-term trends in SST in the same area.

\section{RESULTS}

\section{Tag release and recovery}

The 5 chum salmon with data storage tags were released in the Bering Sea during a $10 \mathrm{~d}$ period from 3 to 12 July 1998 (Table 2). The fish were caught by surface longline gear at night and released with minimal handling after length and age data were collected. SST at the release site was also recorded. The fish were at liberty for 62 to $118 \mathrm{~d}$ and were recovered on the northeast and west coasts of Japan (Fig. 1A). The fish were measured and sexed upon recovery and the data storage tags were returned to the laboratory for data recovery (Table 3).

\section{Temperature data}

Immediately after release, each fish experienced a short period of near constant temperature lasting 1 to $3 \mathrm{wk}$, which we assume reflects a cessation of diving activity. This was followed by a pattern of diel variation in tem-

Table 2. Information for chum salmon released in the Bering Sea. Age given as yr in freshwater (FW) and marine (MAR) environments. SST: sea surface temperature. Age designation follows Koo (1962)

\begin{tabular}{|lccccccc}
\hline Fish & Tag & Fork length $(\mathrm{mm})$ & Age (yr, FW/MAR) & Release date & Local time & Location & SST $\left({ }^{\circ} \mathrm{C}\right)$ \\
\hline 1 & 255 & 560 & 0.3 & $04 \mathrm{Jul} 98$ & $21: 30 \mathrm{~h}$ & $53^{\circ} 30^{\prime} \mathrm{N}, 179^{\circ} 30^{\prime} \mathrm{W}$ & 5.9 \\
2 & 259 & 622 & 0.3 & $03 \mathrm{Jul} 98$ & $21: 30 \mathrm{~h}$ & $52^{\circ} 30^{\prime} \mathrm{N}, 179^{\circ} 30^{\prime} \mathrm{W}$ & 7.4 \\
3 & 271 & 592 & 0.3 & $06 \mathrm{Jul} 98$ & $22: 15 \mathrm{~h}$ & $55^{\circ} 30^{\prime} \mathrm{N}, 179^{\circ} 30^{\prime} \mathrm{W}$ & 6.3 \\
4 & 274 & 680 & 0.4 & $07 \mathrm{Jul} 98$ & $22: 30 \mathrm{~h}$ & $56^{\circ} 30^{\prime} \mathrm{N}, 179^{\circ} 30^{\prime} \mathrm{W}$ & 6.9 \\
5 & 299 & 577 & 0.3 & $12 \mathrm{Jul} 98$ & $22: 30 \mathrm{~h}$ & $56^{\circ} 30^{\prime} \mathrm{N}, 177^{\circ} 30^{\prime} \mathrm{W}$ & 7.1 \\
\hline
\end{tabular}

Table 3. Information for chum salmon captured along the Japanese coast and Sea of Japan

\begin{tabular}{|c|c|c|c|c|c|c|c|c|}
\hline \multirow[t]{2}{*}{ Fish } & \multirow[t]{2}{*}{ Tag } & \multicolumn{2}{|c|}{ Recapture } & \multirow{2}{*}{$\begin{array}{l}\text { Days at large } \\
\text { (d) }\end{array}$} & \multirow{2}{*}{$\begin{array}{l}\text { Distance traveled } \\
\qquad(\mathrm{km})\end{array}$} & \multirow{2}{*}{$\begin{array}{l}\text { Fork length } \\
\quad(\mathrm{mm})\end{array}$} & \multirow[t]{2}{*}{ Sex } & \multirow{2}{*}{$\begin{array}{l}\text { Data interval } \\
\text { (min) }\end{array}$} \\
\hline & & Date & Location & & & & & \\
\hline 1 & 255 & 10 Oct 98 & $44^{\circ} 13^{\prime} \mathrm{N}, 143^{\circ} 40^{\prime} \mathrm{E}$ & 98 & 2.845 & 610 & $\mathrm{~m}$ & 30 \\
\hline 2 & 259 & 04 Sep 98 & $42^{\circ} 39^{\prime} \mathrm{N}, 143^{\circ} 31^{\prime} \mathrm{E}$ & 62 & 2.942 & 650 & $\mathrm{~m}$ & 15 \\
\hline 3 & 271 & 01 Nov 98 & $36^{\circ} 47^{\prime} \mathrm{N}, 136^{\circ} 05^{\prime} \mathrm{E}$ & 118 & 3.907 & 610 & $\mathrm{~m}$ & 30 \\
\hline 4 & 274 & 24 Sep 98 & $44^{\circ} 30^{\prime} \mathrm{N}, 145^{\circ} 20^{\prime} \mathrm{E}$ & 79 & 2.779 & 716 & $\mathrm{~m}$ & 30 \\
\hline 5 & 299 & 05 Oct 98 & $43^{\circ} 41^{\prime} \mathrm{N}, 145^{\circ} 09^{\prime} \mathrm{E}$ & 85 & 2.969 & 590 & $\mathrm{f}$ & 30 \\
\hline
\end{tabular}


perature, suggesting daily vertical excursions to colder water (Fig. 2). The excursions into colder water occurred during the day and represented daily temperature ranges of $\sim 10^{\circ} \mathrm{C}$. After this initial period, all 5 tags recorded a short 2 to $5 \mathrm{~d}$ period of relatively cool water temperatures during both day and night. This occurred at various times for each tag, but is seen for all tags from late August to mid-September. A trend of increased night-time temperatures was apparent as the fish migrated toward Japan, and with the exception of tag 271, warmer water and less frequent or inconsistent daily temperature excursions were recorded during the weeks prior to recapture. Tag 271, carried by the only fish captured on the west coast of Japan, recorded a $\sim 1$ mo period of diel dives into low temperature water, with daily temperature ranges of $\sim 15^{\circ} \mathrm{C}$.

The tag temperature data were also summarized as daily maximum night-time temperatures to enable location of the fish with reference to SST. This of course assumes that the fish come to the surface at night and is subject to the constraints placed on the fish by its own swimming potential and its proximity to land. These data show more clearly the trend of increased temperature experienced by the fish as their

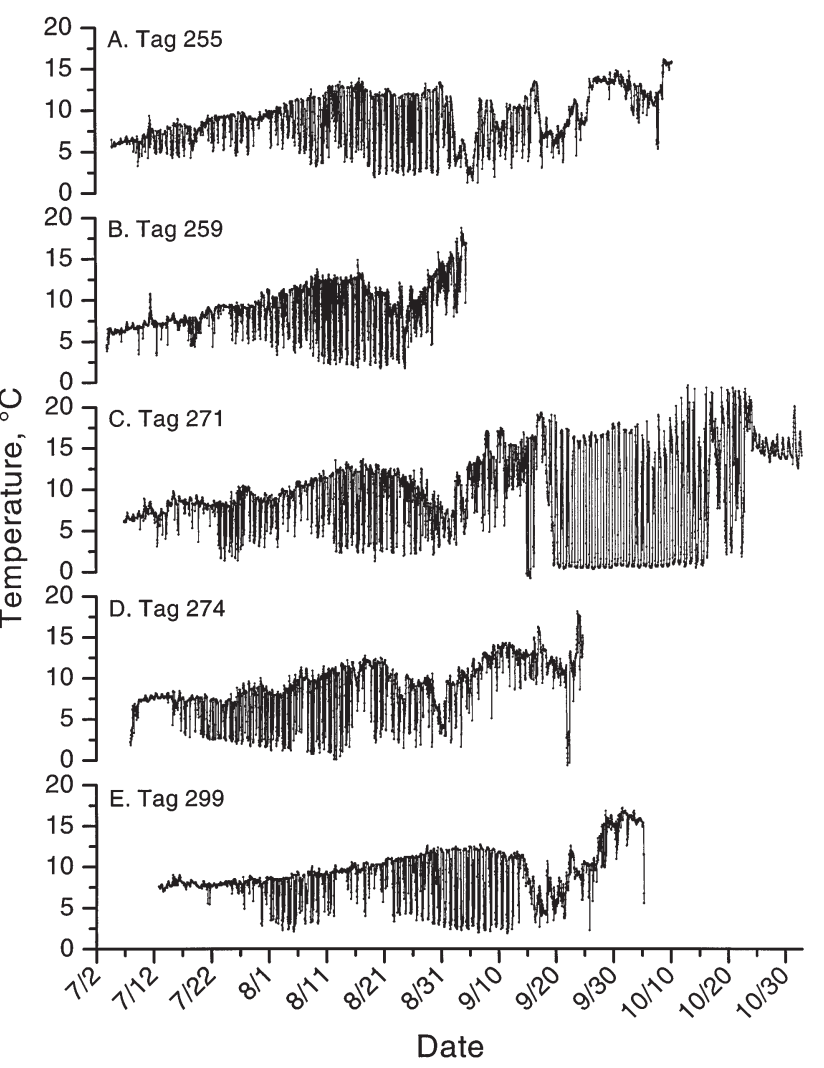

Fig. 2. Tag temperatures versus local date and time. Tags: (A) 255, (B) 259, (C) 271, (D) 274, (E) 299 migrations progressed (Fig. 3). They also show the cold-water period during late August to mid-September recorded by all 5 tags. These data are compared with the SST at the release location for each tag (Fig. 3). Night-time tag temperatures were nearly the same as the SST at the release sites for the first $\sim 3$ to 5 wk at liberty, after which tag temperatures increased at a faster rate.

\section{Difference analysis}

The computational difference analysis yielded inconsistent results among tags. The intention of the analysis was to look for patterns of progress across thermal gradients as the fish migrated to home waters. By dividing the data into night and day differences, we intended to evaluate progress made during the respective periods. However, any underlying trends in night and day differences were obscured by the daily variation in temperature from daytime dives. This highlights the inaccuracies in our assumptions about when each fish was experiencing dawn and dusk. The analysis showed patterns of large positive and negative differences that could not be explained by horizontal

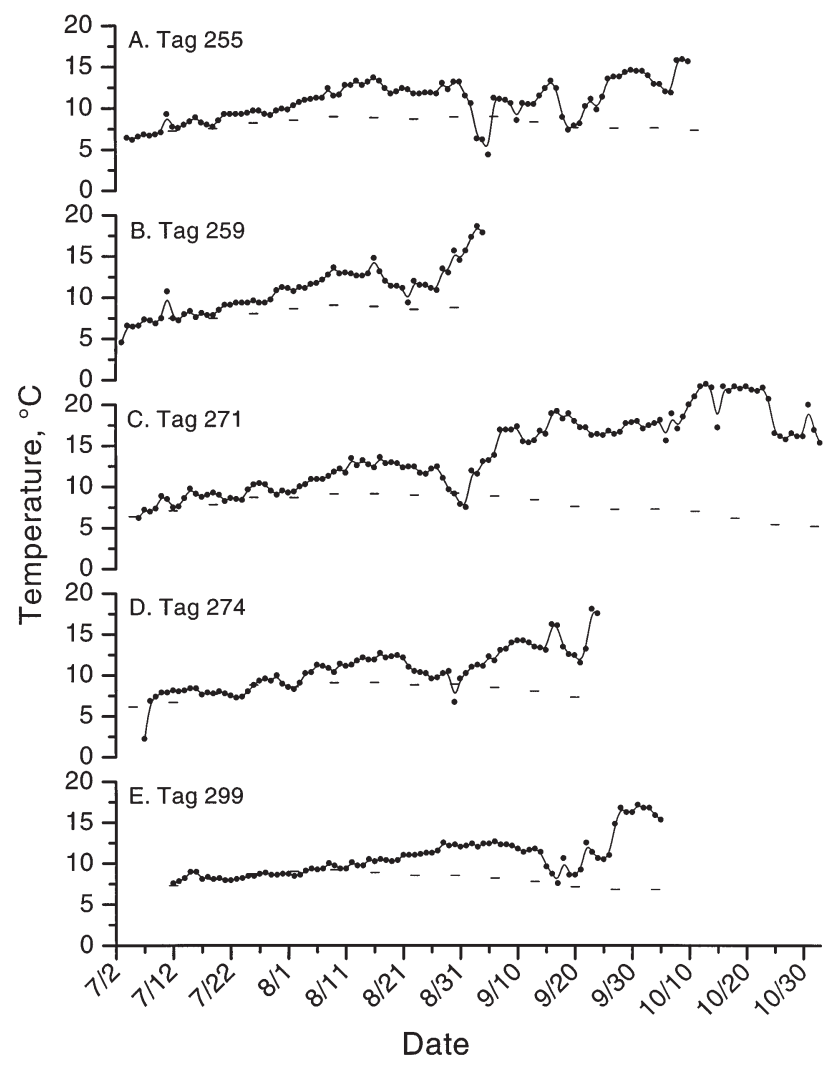

Fig. 3. Daily maximum night-time tag temperatures. Horizontal bars, mean weekly SST at release locations. Tags: (A) 255, (B) 259, (C) 271, (D) 274, (E) 299 
movements of the fish (Fig. 4). For example, the differences for tag 271 were $\sim 10^{\circ} \mathrm{C}$. In some cases night-time differences tended to be positive, e.g. tags 259 and 271 , whereas in others, daytime differences were positive, e.g. tag 274. The shortcomings in this analysis therefore illustrate some important properties of the data.

Tag temperatures were nearly constant during the night, when the maximum temperatures were usually experienced by the fish. This can be seen for 4 days in August in the data from tag 259 (Fig. 5). The progression of temperature change also shows that the assumed time of dusk may be in error for this tag, as it did not characterize the transition period from daytime diving to night-time surface swimming. The opposite effect can be seen in the data for tag 274, where it is not clear whether dawn has been estimated properly or if the fish is just starting its dives early (Fig. 6). Though these data reinforce the assertion that the fish are at the surface at night, they also show the ineffectiveness of the computational difference approach.

The observational difference analysis shows that during the key open-ocean migrational periods, greater progress against thermal gradients was made

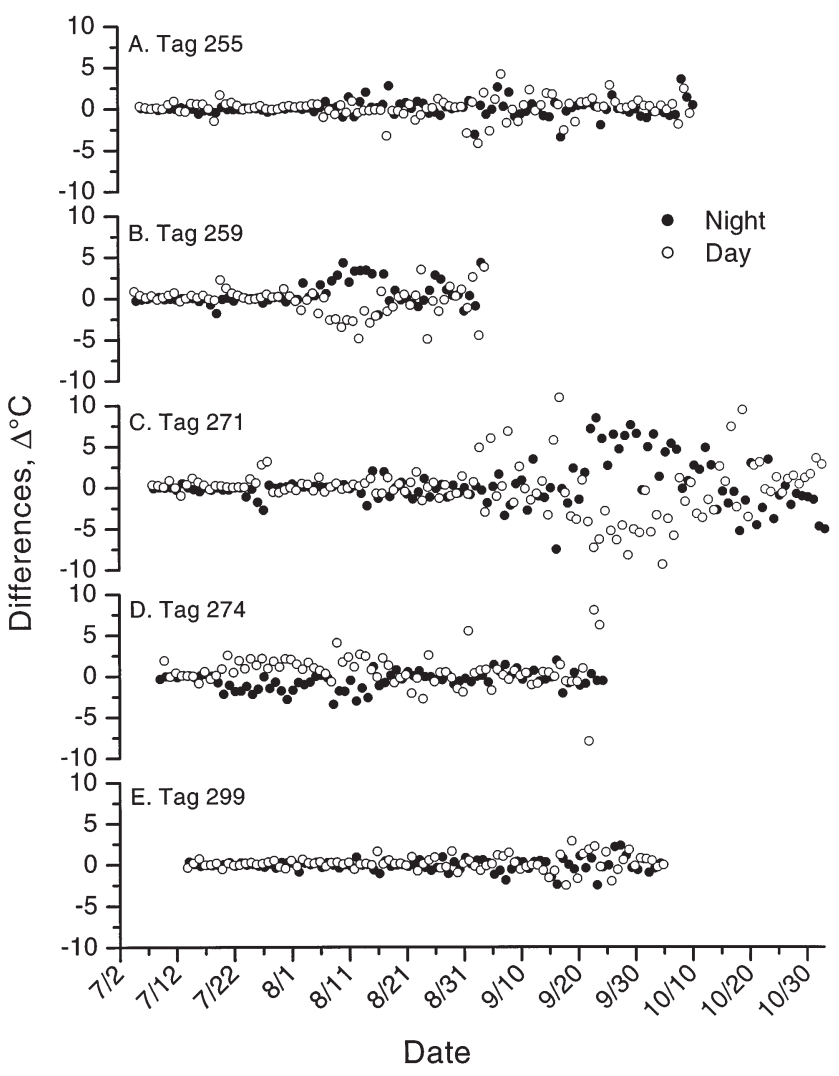

Fig. 4. Computed 'dusk to dawn' (night) and 'dawn to dusk' (day) temperature differences. Tags: (A) 255, (B) 259, (C) 271, (D) 274, (E) 299 during the day. For the periods described in Table 1, 'dusk to dawn' (i.e. night) and 'dawn to dusk' (i.e. day) temperature differences were computed for each tag (Fig. 7). The daytime differences were all larger in magnitude and positive compared to the night differences, which were smaller and negative in all but 1 case, i.e. tag 259. Moreover, with the exception of tag 259, these comparisons were statistically significant (Table 4).

\section{Sea surface temperature}

The large-scale movements of each tagged fish can be followed in the weekly OI SST data. However, the cold water periods late in the migrations were not well explained by these data, and were examined in greater detail using other data. Isotherms marking the weekly mean maximum night-time temperatures for tag 255 are plotted in Fig. 8. In the first panel of Fig. 8, temperature at the release site correlates with tag temperature at release. Through the next $7 \mathrm{wk}$ the isotherms move to the southwest, defining a broad front of possible migration routes. However, by the tenth week the weekly mean maximum night-time tag temperature declines to $9.3^{\circ} \mathrm{C}$ from the previous week's level of $12^{\circ} \mathrm{C}$. This decline in temperature corresponds to the cold-water period mentioned above. This colder isotherm is present in the OI SST data for the Gulf of Shelekhova (Sea of Okhotsk) and in the Bering Sea. During the next $3 \mathrm{wk}$, the isotherms marking the mean maximum night-time tag temperatures can be found in the Kuril Islands, the Sea of Okhotsk, and the Bering Sea. Finally, in the last panel of Fig. 8, the isotherm during the week of recapture correlates with the recapture location. The same analysis for tag 259 can be found in Fig. 9. In the sixth week of the analysis, the isotherm marking the mean night-time maximum from the tag is at $13^{\circ} \mathrm{C}$, whereas during the following $2 \mathrm{wk}$ the temperature drops to $12^{\circ} \mathrm{C}$. The analysis for tag 271 shows the progression of temperatures both before and after the fish likely made contact with the Japanese coast (Fig. 10). In the first part of the migration, the magnitude of the isotherms decreased from $12.7^{\circ} \mathrm{C}$ in Week 7 , to 11.6 and $10.6^{\circ} \mathrm{C}$ during Weeks 8 and 9 respectively. These temperatures can be found in either the Sea of Okhotsk or Bering Sea, as has been shown with tags 255 and 259. In the second part of the migration, temperatures experienced rise to $22^{\circ} \mathrm{C}$ on both sides of the Japanese Islands. The difference between the final tag temperature isotherm and the recovery location may be due to a reporting problem, and it would appear that the fish was moving north in the Sea of Japan during its final weeks. The trends for the remaining 2 tags are similar overall. The key 


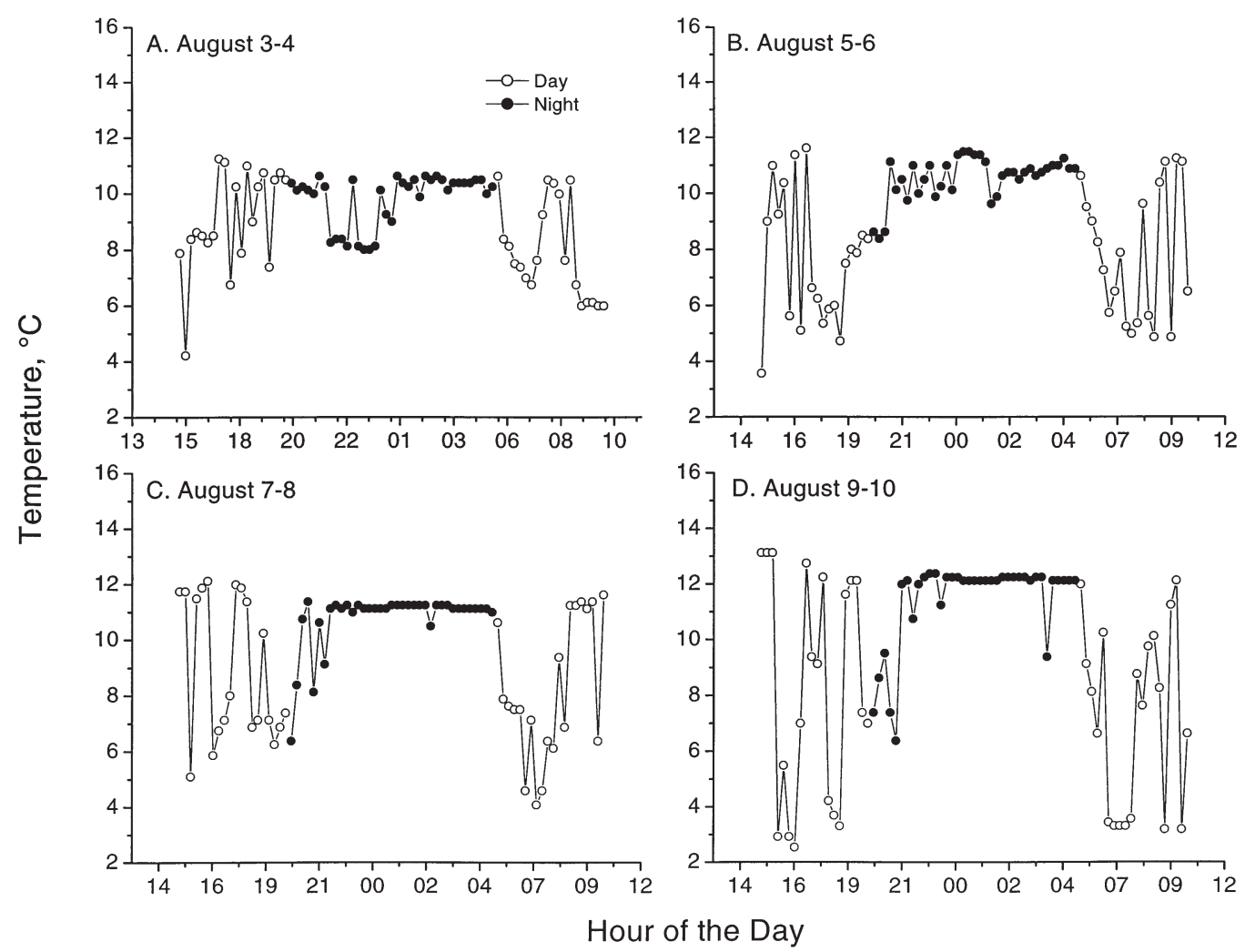

Fig. 5. Tag 259: temperature every $15 \mathrm{~min}$ for 3 to 10 August
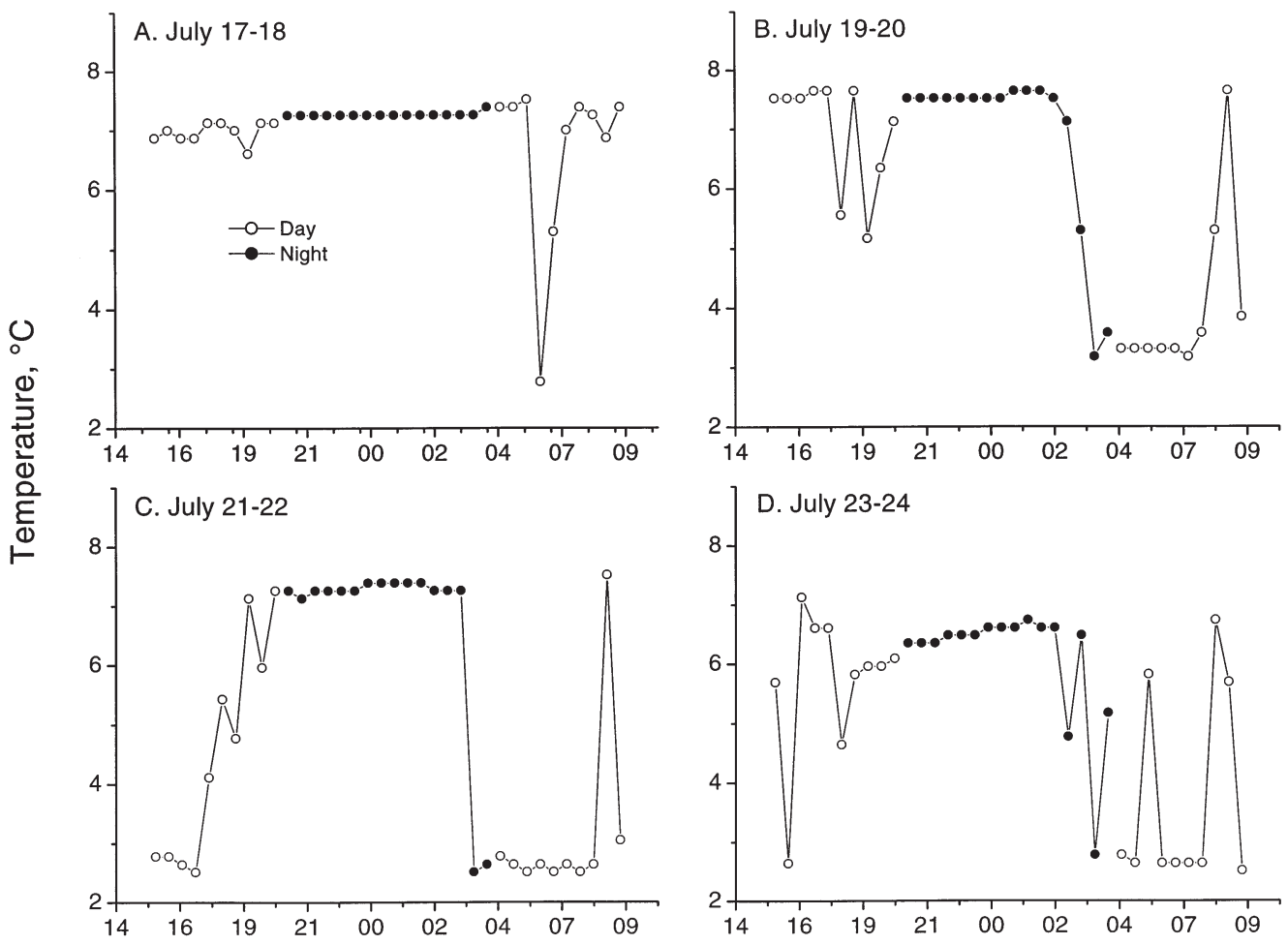

Hour of the Day

Fig. 6. Tag 274: temperature every $30 \mathrm{~min}$ for 17 to 24 August 


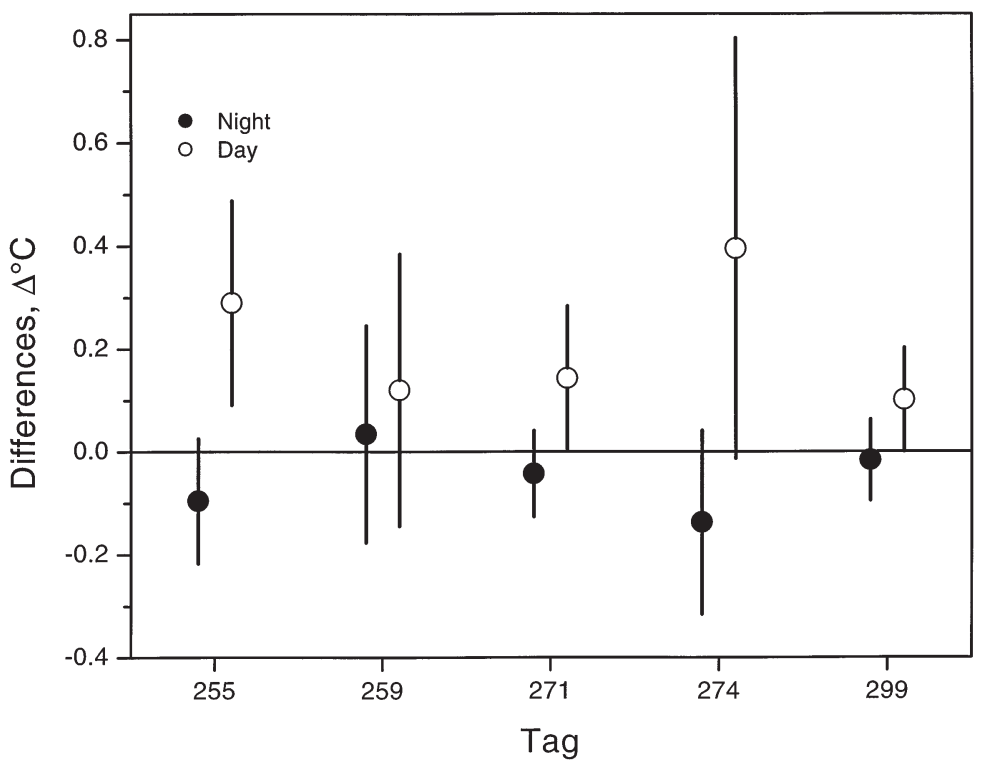

Fig. 7. Observed 'dusk to dawn' (night) and 'dawn to dusk' (day) temperature differences for key migration periods. Error bars, 95\% confidence intervals

weeks with respect to the cold water period, shown by the progression and regression of maximum tag temperature, are weeks 7 to 10 (Fig. 11) for tag 274, and weeks 8 to 11 (Fig. 12) for tag 299.

The large-scale sea surface temperature analysis highlights our interest in the cold-water period and what it may suggest about the migration routes taken by the fish. From this analysis, we are left with limited possible explanations for the progression of temperatures experienced by the fish. A direct migration route from release to recovery site (Fig. 1A) would suggest that the fish either reversed course and migrated back from whence it came, to find cooler water in the Bering Sea - which we deem unlikely - or it encountered colder water in the vicinity of either the Kuril Islands or in the Sea of Okhotsk. Cold waters are not evident in the OI SST data around the Kuril Islands, which does not support the case for a direct migration route. Alternatively, the fish may have taken a westward course, towards the coast of the Kamchatka Peninsula, and then followed the coast into the Sea of Okhotsk, coming into contact with the cold water that appears in the OI SST data, especially towards the Gulf of Shelekhova.

However, we still have a number of concerns about the OI SST dataset and how well it represents the finescale movements of the fish, especially in regard to the cold-water period. To address these concerns, we first examined the tag temperature records during the cold water periods in greater detail and we then looked at other sources of SST data to assess where cold surface water may be occurring in the region. We were interested in seeing if the diel temperature data patterns for the fish were preserved during the cold water periods. If they were preserved it would support the contention that SST reflects where the fish were; otherwise it would suggest that the fish were remaining at depth all day during the cold water periods, and that distribution cannot be inferred from the SST data. For the most part, the diel behavior is preserved during this period; however, there are some exceptions. For tag 259, the data pattern is preserved as the fish dove to water colder than $5^{\circ} \mathrm{C}$ during the day and stayed in water that ranged from $\sim 7$ to $11^{\circ} \mathrm{C}$ during the night (Fig. 13C). This is generally seen in the data for tag 271 but for a different temperature range (Fig. 13D), and also on some, but not all, days for tags 255 and 274 (Fig. 13B,E). However, it is not clear that the diel pattern is preserved for the early period of tag 255 (Fig. 13A) and for some days for tags 274 and 299 (Fig. 13E,F). While this could represent a cessation of diel vertical movements, it is also possible that the animals continued these movements in a region with a relatively isothermal water column. Such conditions exist in both the northern Sea of Okhotsk and the Kuril Islands.

Higher resolution AVHRR SST data from the same time frames as the cold water showed cold water in the Sea of Okhotsk and the Bering Sea. Temperatures of $\leq 7^{\circ} \mathrm{C}$ were only found on the western shore of the Kamchatka Peninsula and in the Bering Sea during the week of 2 September (Fig. 14A) which is of relevance to tags 255, 271, and 274. Colder water was more widespread in the Sea of Okhotsk during the week of 16 September, but still not found elsewhere in the study area (Fig. 14B). These data are relevant to the coldwater markers for tags 255 and 299. The 2 weeks highlighted and relevant to cold August tag temperatures were the weeks of 19 August (Fig. 14C) and 26 August (Fig. 14D). In both cases, cold surface waters were only detected in the Bering Sea and the Gulf of Shelekhova.

Table 4. Results of ANOVA comparing night versus day temperature differences. Values significant at $p=0.05$ are in bold

\begin{tabular}{|ccrc|}
\hline Tag & $\begin{array}{c}\text { df } \\
\text { (within, between) }\end{array}$ & $F$ & $p$ \\
\hline 255 & 58,1 & 10.55 & $\mathbf{0 . 0 0 2}$ \\
259 & 58,1 & 0.25 & 0.622 \\
271 & 94,1 & 4.69 & $\mathbf{0 . 0 3 3}$ \\
274 & 30,1 & 5.46 & $\mathbf{0 . 0 2 6}$ \\
299 & 58,1 & 4.01 & $\mathbf{0 . 0 5 0}$ \\
\hline
\end{tabular}



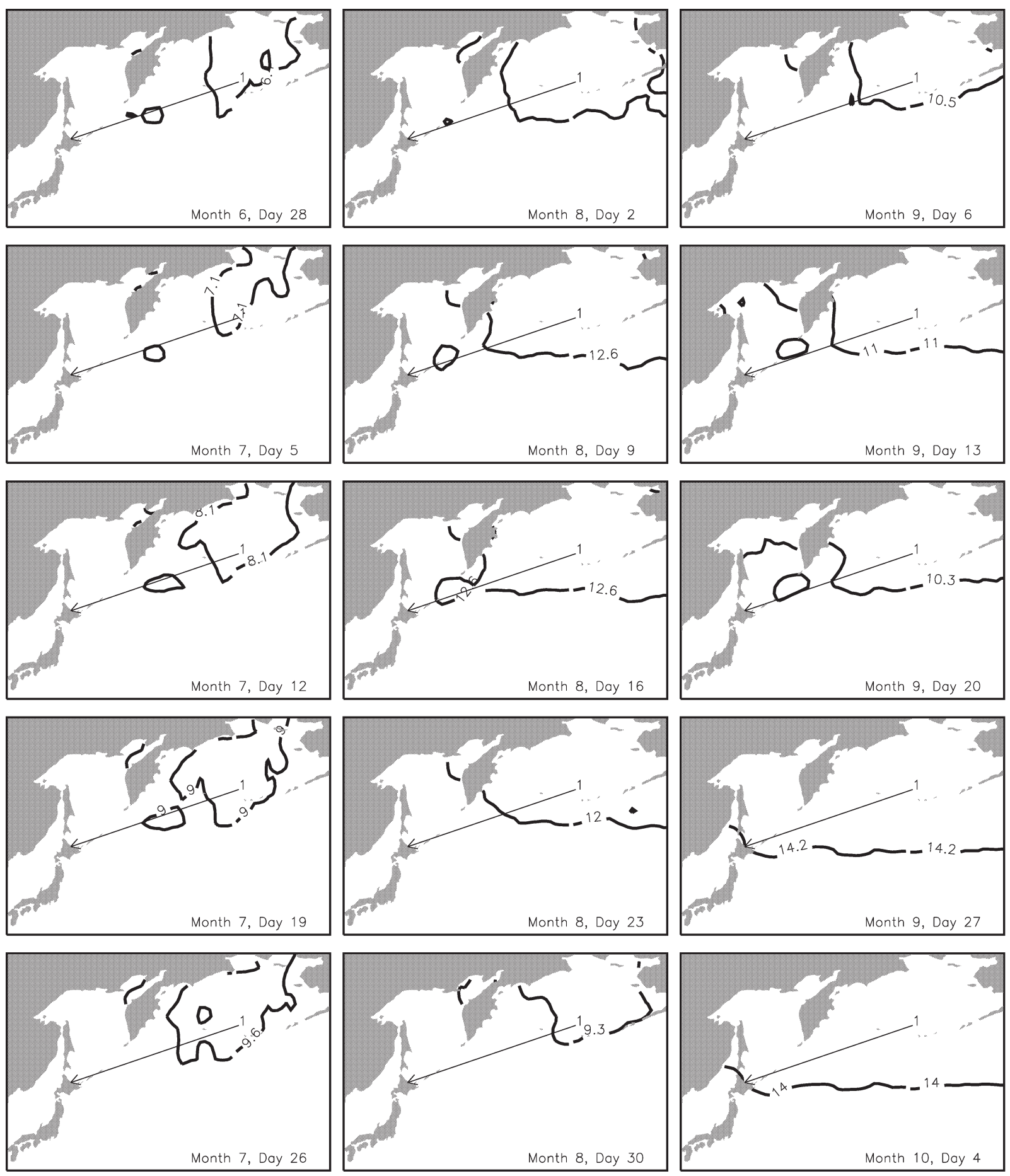

Fig. 8. Contours of weekly mean maximum night-time temperatures $\left({ }^{\circ} \mathrm{C}\right)$ for tag 255 . Arrow, release to recovery locations

These data are consistent with the lower resolution OI data, suggesting that the fish may have made an excursion into the Sea of Okhotsk.

The in situ temperature observations for the region show that water temperatures consistent with the cold water period occurred episodically in the area of the Kuril Islands, which supports the possibility of a direct migration route for the fish. Minimum temperatures for August and September at a number of locations around the Kuril Islands were $<7^{\circ} \mathrm{C}$, although nearly 

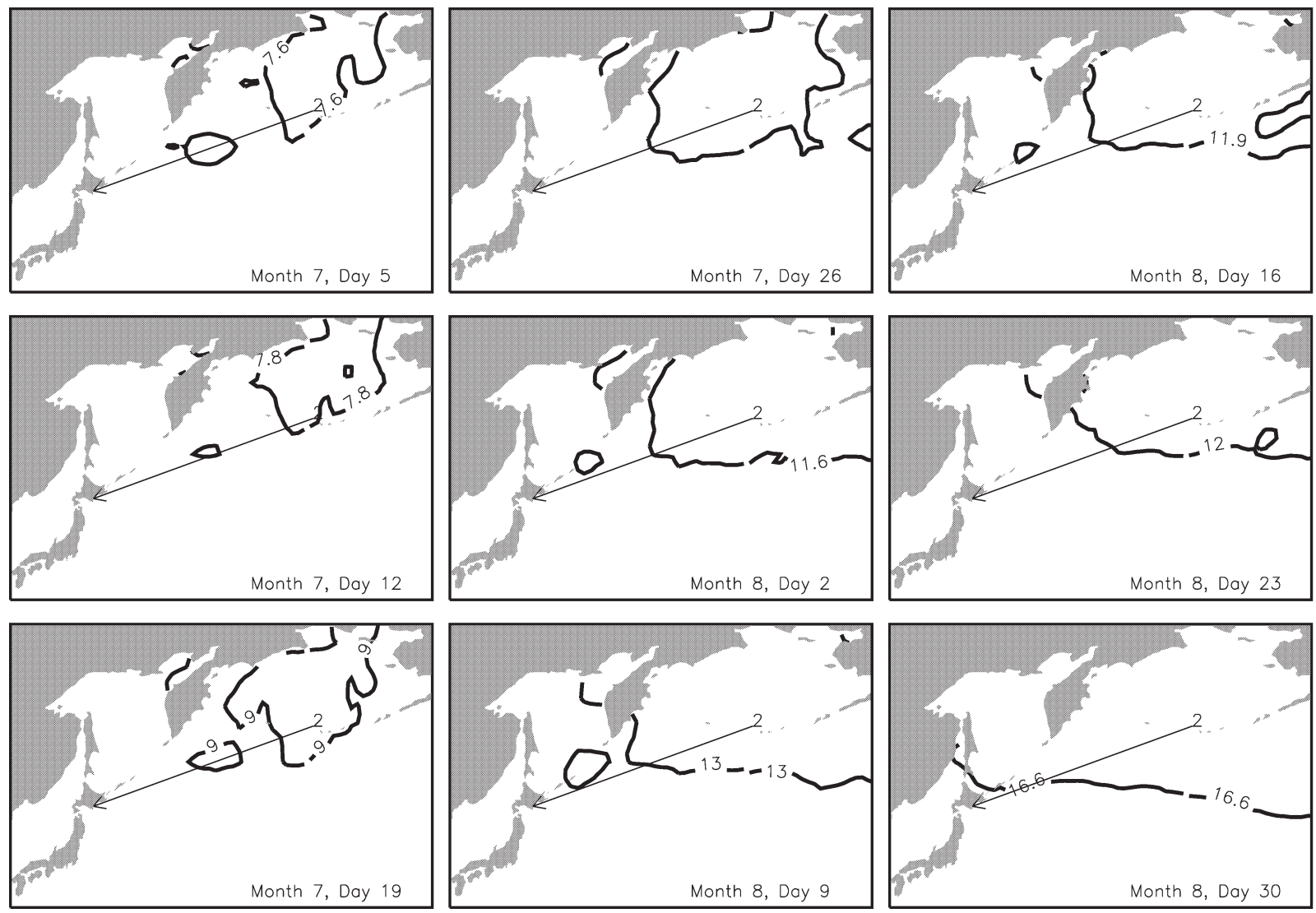

Fig. 9. Contours of weekly mean maximum night-time temperatures $\left({ }^{\circ} \mathrm{C}\right)$ for tag 259 . Arrow, release to recovery locations

all these locations had monthly means $>7^{\circ} \mathrm{C}$ (Table 5). Climatological data for the region suggests upwelling along the Kurils chain is a consistent feature of the region (Table 6). In these areas, either upwelling or mixing through the narrow passages to the Sea of Okhotsk may result in low SST (Kono \& Kawasaki 1997). Thus, it is difficult to interpret the data we have for 1998 since it suggests that the cold surface water that did occur in the area was transient.

\section{DISCUSSION}

The main finding of our study was that chum salmon appeared to make more migrational progress in the open ocean during daylight hours, which supports the hypothesis that they use a light-mediated orientation mechanism, such as a sun compass. The fish undoubtedly swim at night as well, but it is not clear that nighttime movements are directed. During most nights, temperature remained in a narrow range or stayed the same for long periods of time. Night-time temperatures were also among the highest temperatures experienced by the fish. This suggests that they were near the surface at night and likely remained at a constant depth for long periods of time, which is supported by recent reports of experiments with depth recoding tags (Ishida et al. 1998, Wada \& Ueno 1999). The slight cooling of the tags over the course of the night may be related to daily variation in surface water temperatures, but the warming that occurred between the beginning and end of the day exceeded a proportional increase that might be expected if the fish were staying in one location. In some cases the fish showed large daily ranges in temperature, implying that daytime diving excursions may be to considerable depths. This is also supported by the reports of Ishida et al. (1998) and Wada \& Ueno (1999), who routinely found fish between 0 and $60 \mathrm{~m}$. The large number of dives made by the fish each day may indicate that headings are developed during dives and ascents with the help of the position of the sun. If the fish utilize polarized light (Flamarique et al. 1993) this mode of orientation could

Fig. 10. Contours of weekly mean maximum night-time temperatures $\left({ }^{\circ} \mathrm{C}\right)$ for tag 271 . Arrow, release to recovery locations 

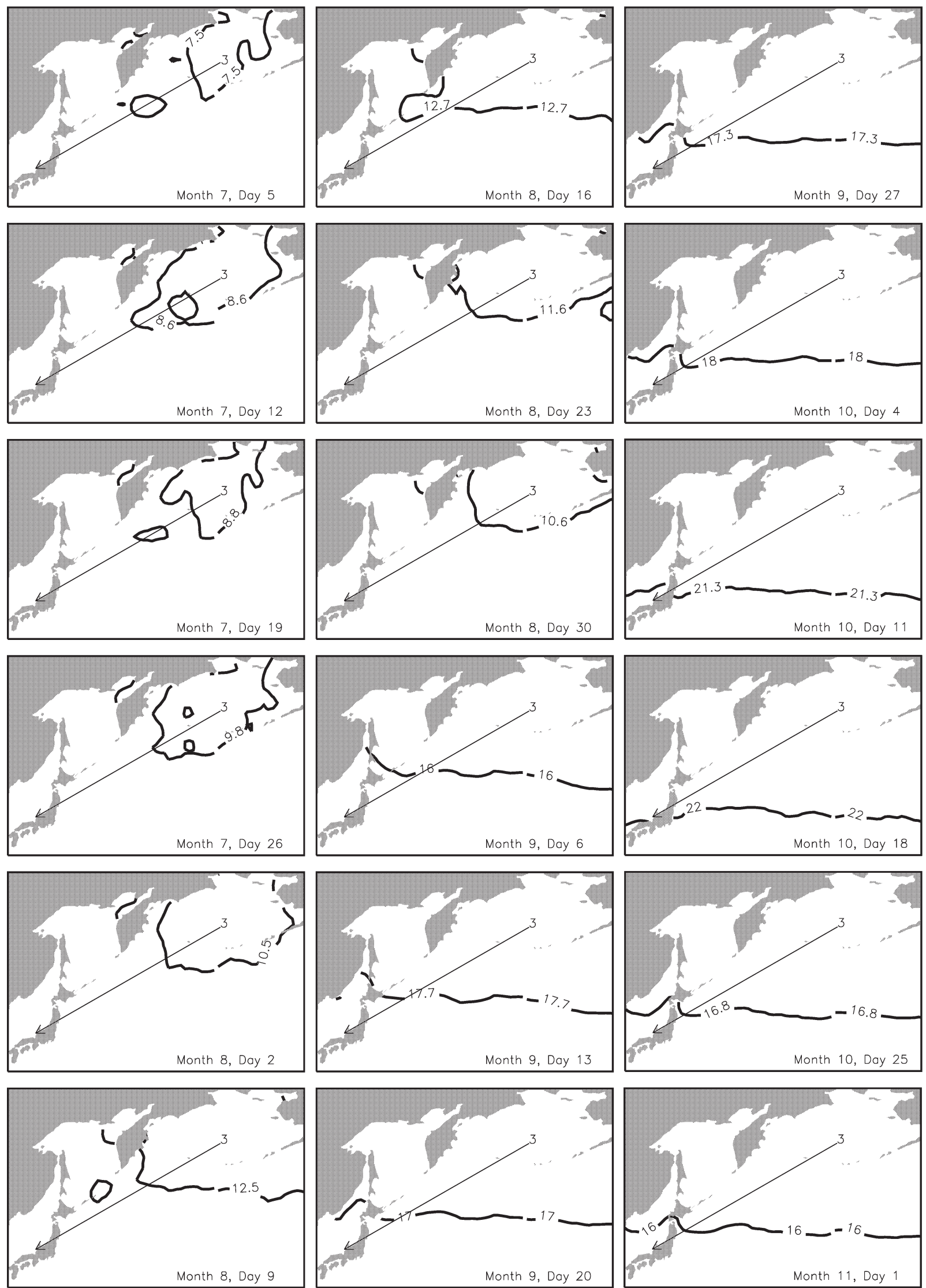

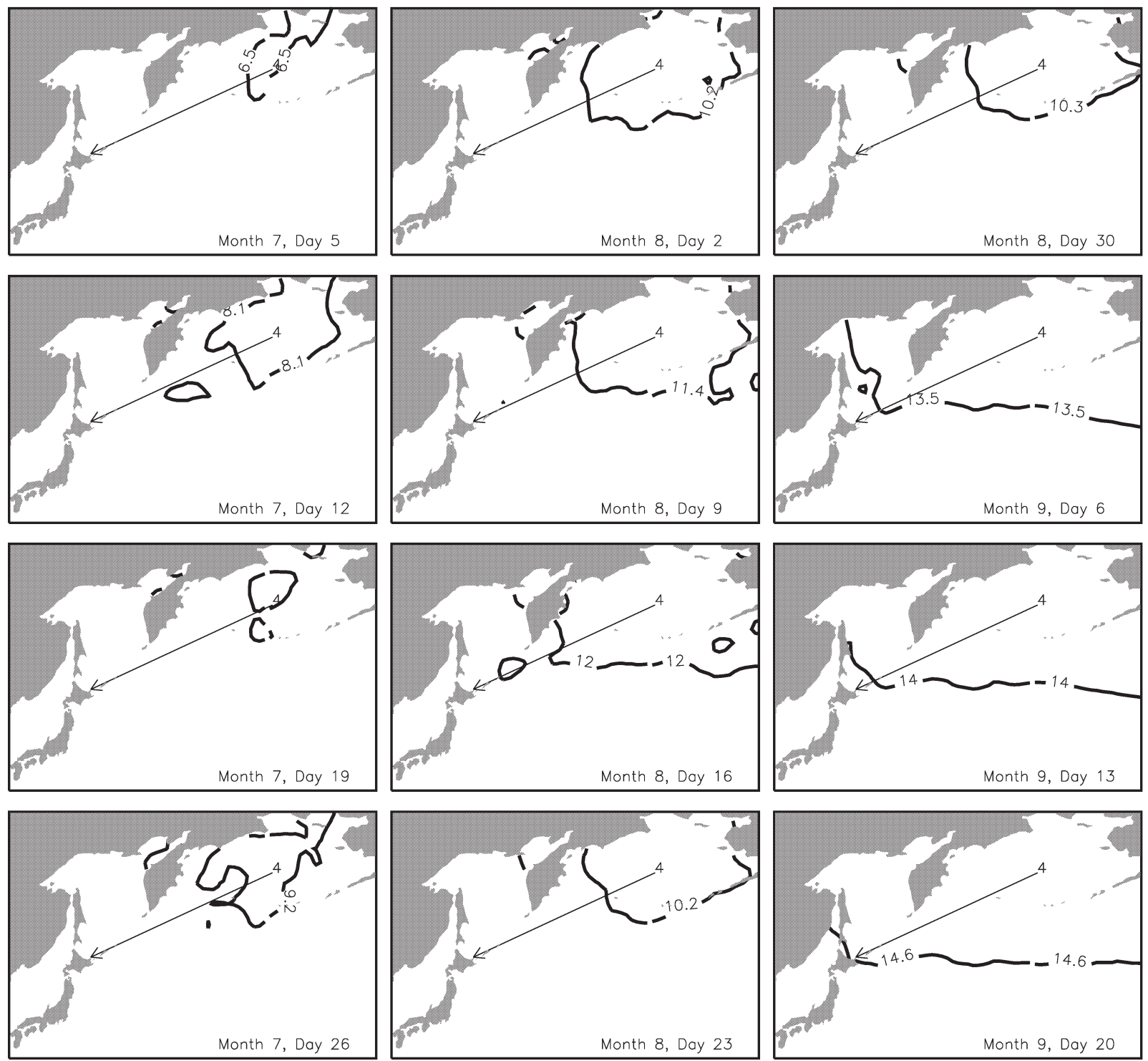

Fig. 11. Contours of weekly mean maximum night-time temperatures $\left({ }^{\circ} \mathrm{C}\right)$ for tag 274 . Arrow, release to recovery locations

also be robust to varying conditions caused by cloud cover and water column clarity, which affect visible light. This would appear to be a possibility given the anatomical features of the pineal window in related species (Nordtug et al. 1994). Additional data on the actual depths occupied by the fish in respect to the distribution of light will provide important insights on the role of light orientation at sea.

Studies of tagged chum salmon have been interpreted to suggest that celestial and magnetic compass cues are the primary modes of open-ocean orientation. The movements of 4 species of Oncorhynchus, including chum salmon, were tracked with ultrasonic tags yielding a detailed account of the movement of the fish for a few days after tagging (Ogura et al. 1992, 1995). The results showed that the fish maintained a compass direction during both day and night, suggesting that celestial cues were not important to open-ocean orientation. However, many fish did change direction during the tracking period, which raises questions as to whether the headings the fish choose were purposeful. The nature of magnetic orientation was tested with chum salmon by tracking fish fitted with a tag that disturbed the magnetic field around the fish (Yano et al. 1997). Because headings of the fish did not change despite changes in the local magnetic field, it was concluded that the fish were not utilizing magnetic orientation. However, these studies 

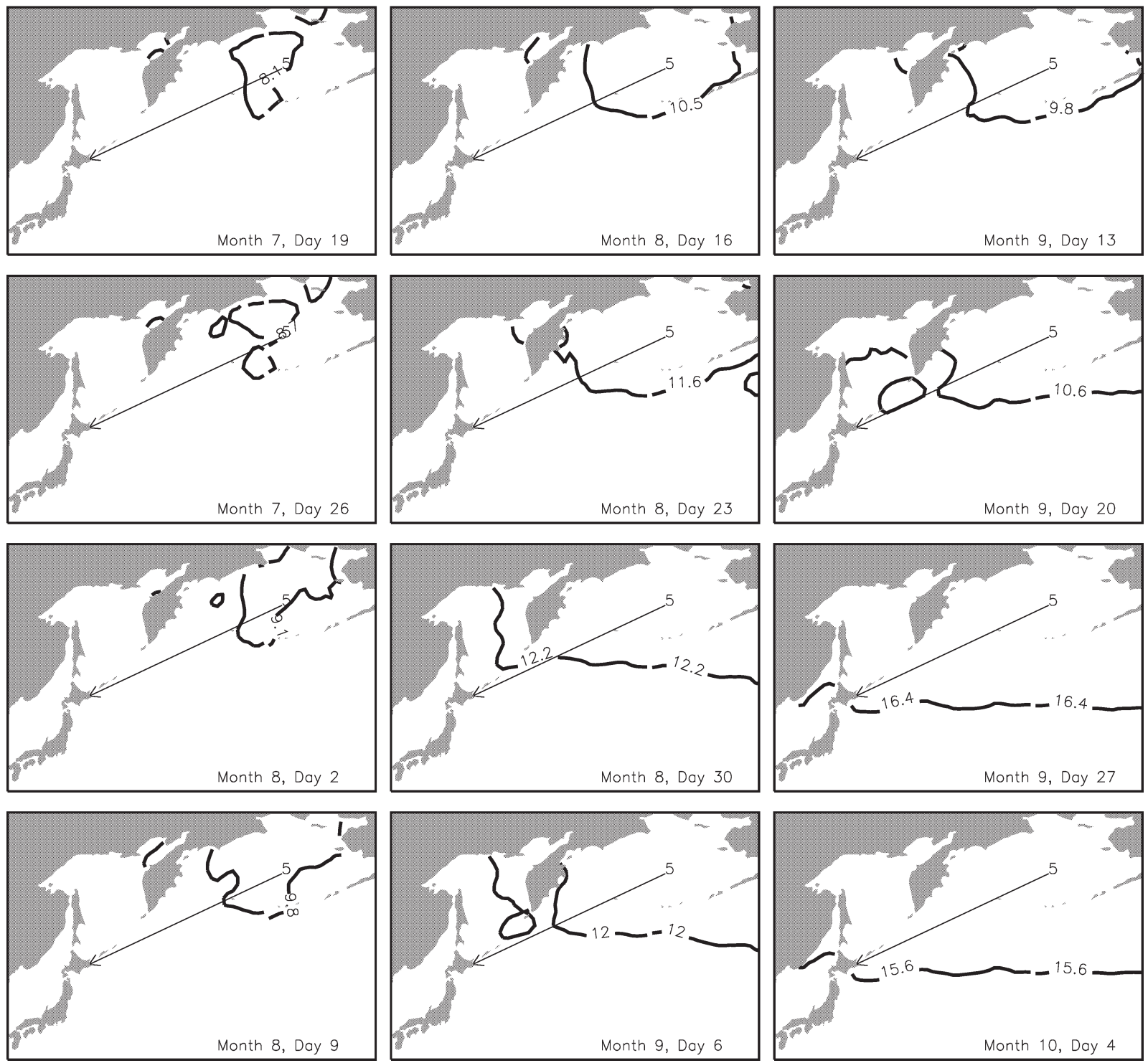

Fig. 12. Contours of weekly mean maximum night-time temperatures $\left({ }^{\circ} \mathrm{C}\right)$ for tag 299 . Arrow, release to recovery locations

only followed the tagged fish for a short period of time, and, as shown here and by Walker et al. (2000), it may take up to $14 \mathrm{~d}$ before a fish resumes its normal diving behavior after the trauma of tag application. If diving behavior is disturbed, it is reasonable to suggest that swimming and magnetic orientation may be disturbed as well.

Navigation in animals involves the determination of bearings to a migrational goal and the use of a compass to maintain those bearings. A number of compass senses may be used and learned by animals and they often support each other in some hierarchy. In most cases, the celestial compass is the primary compass, with the organism only relying on the magnetic com- pass when celestial cues are unavailable (Gould 1998). Furthermore, though the magnetic compass is dependant upon the presence of magnetite, variants of magnetic orientation often utilize induction or paramagnetic interaction that occurs when certain pigments are stimulated by short-wavelength light (Deutschlander et al. 1999b). Research on newts suggests that extraocular receptors in the pineal complex or deeper in the brain control light-dependent magnetic orientation (Deutschlander et al. 1999a). Our assertion that chum salmon orient in the open ocean using light does not preclude their use of magnetic fields to develop migration headings at some level. Though magnetite and the pineal organ exist in salmon, greater attention to the 


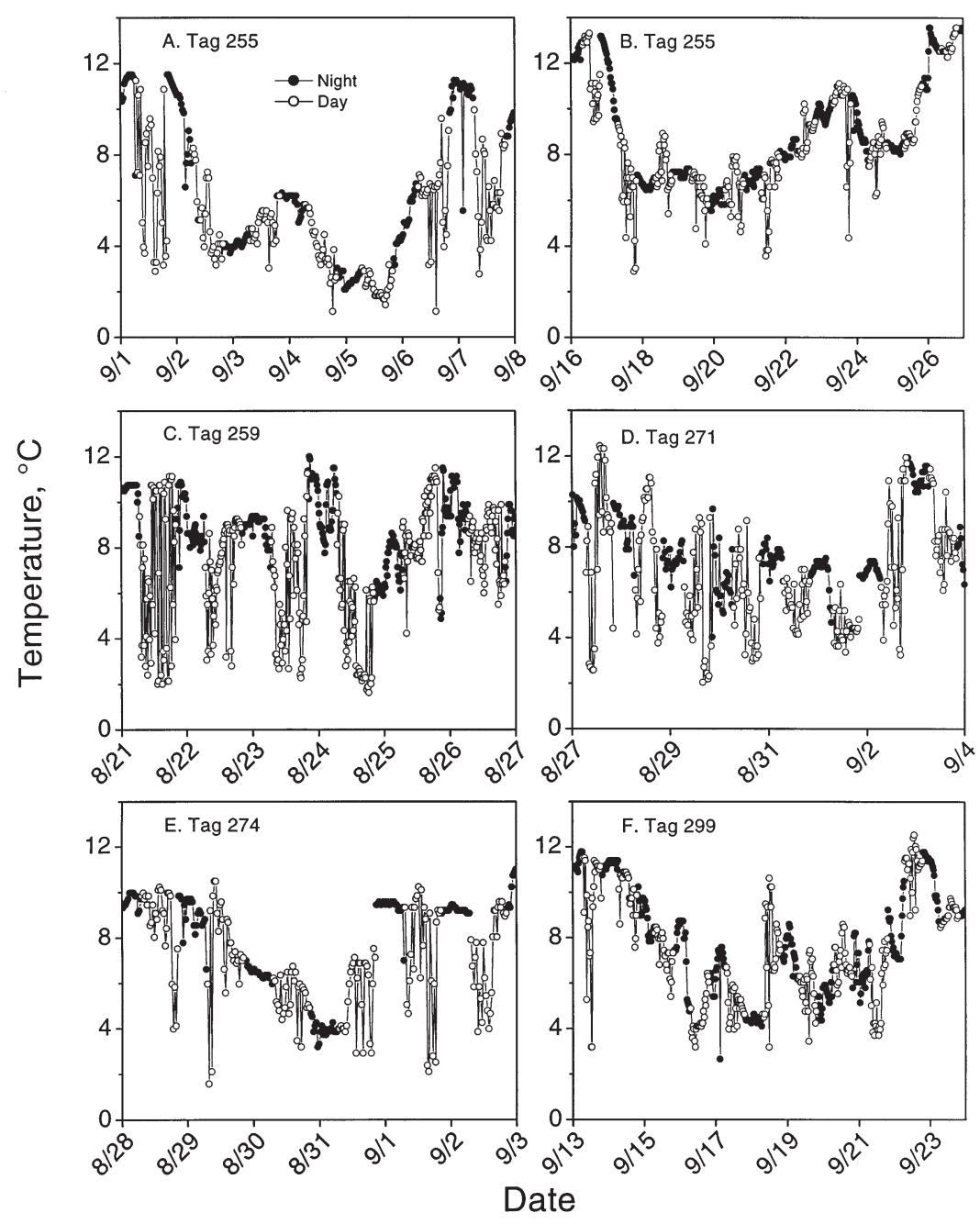

Fig. 13. Tag temperatures during cold water period. Tags: (A, B) 255, (C) 259, (D) 271, (E) 274, (F) 299

functional morphology of these sensory organs may be useful in evaluating the role of magnetic and celestial compasses in salmon migration.

Knowledge of the exact course taken by chum salmon could provide useful information on the mechanisms guiding the open ocean migrations of salmon in general. We can envisage 3 general categories of potential migrational pathways for the fish in this study: a direct course between release and recovery sites; a 2-phase migration with an initial southward migration followed by a westward migration; and, a different 2-phase migration with an initial westward migration followed by movements associated with land boundaries (Fig. 1B). Some guidance mechanisms would appear more applicable to one category versus another.

The direct migration route requires a guidance mechanism that provides a south-west bearing. This could be achieved directly by a sun or magnetic compass; however, navigation using a magnetic compass is less tenable, since the isodynamic regions of the earth's magnetic field curve over the northwest Pacific (Merrill et al. 1996). Tagged salmon experienced progressively warmer waters as they migrated, which may represent preference, as opposed to just tolerance, for certain temperatures (Leggett 1977). If the fish progressively seek warmer water, the migration route could be defined zonally by solar orientation and meridionally by thermal gradients. The direct route may also be guided by geomagnetic navigation.

The other 2 general categories of migration involve initially moving either zonally or meridionally, and they would not constitute navigation since they would not be purposely directed to a particular goal. These migrations would most likely reflect some sort of orientation to, e.g., sun position (zonal movements) and/or incidence angle (meridional movements). If the migration involved an open ocean movement phase followed by a search phase associated with land boundaries (Hansen \& Quinn 1998), then the Kamchatka Peninsula could serve as the land boundary.

The distribution of SST experienced by the fish suggests they either took a direct course past the Kuril Island chain or followed a westward course followed by land boundary movement starting along the Kamchatka Peninsula that possibly resulted in an excursion into the Sea of Okhotsk. The distinct cold water period observed for all fish indicated a short transit through cold water prior to their approach to the warm coastal waters off Japan. If the fish continued to come to the surface at night during the time of the cold water period, as we believe they did during other segments of the migration, then either of our 2 suggested migratory scenarios would be supported by the oceanographic data. However, our interpretations of these alternate possibilities must be tempered due to our inability to reconcile the differences between the temperature datasets. Salmon are present in the Sea of Okhotsk both as adults and juveniles (Shuntov 1989). However, high abundances of salmon are also found in the Kuril Islands chain, which is often an area of upwelling and thus cold surface and near surface waters (Shuntov et al. 1993, Nagasawa et al. 1998). The 

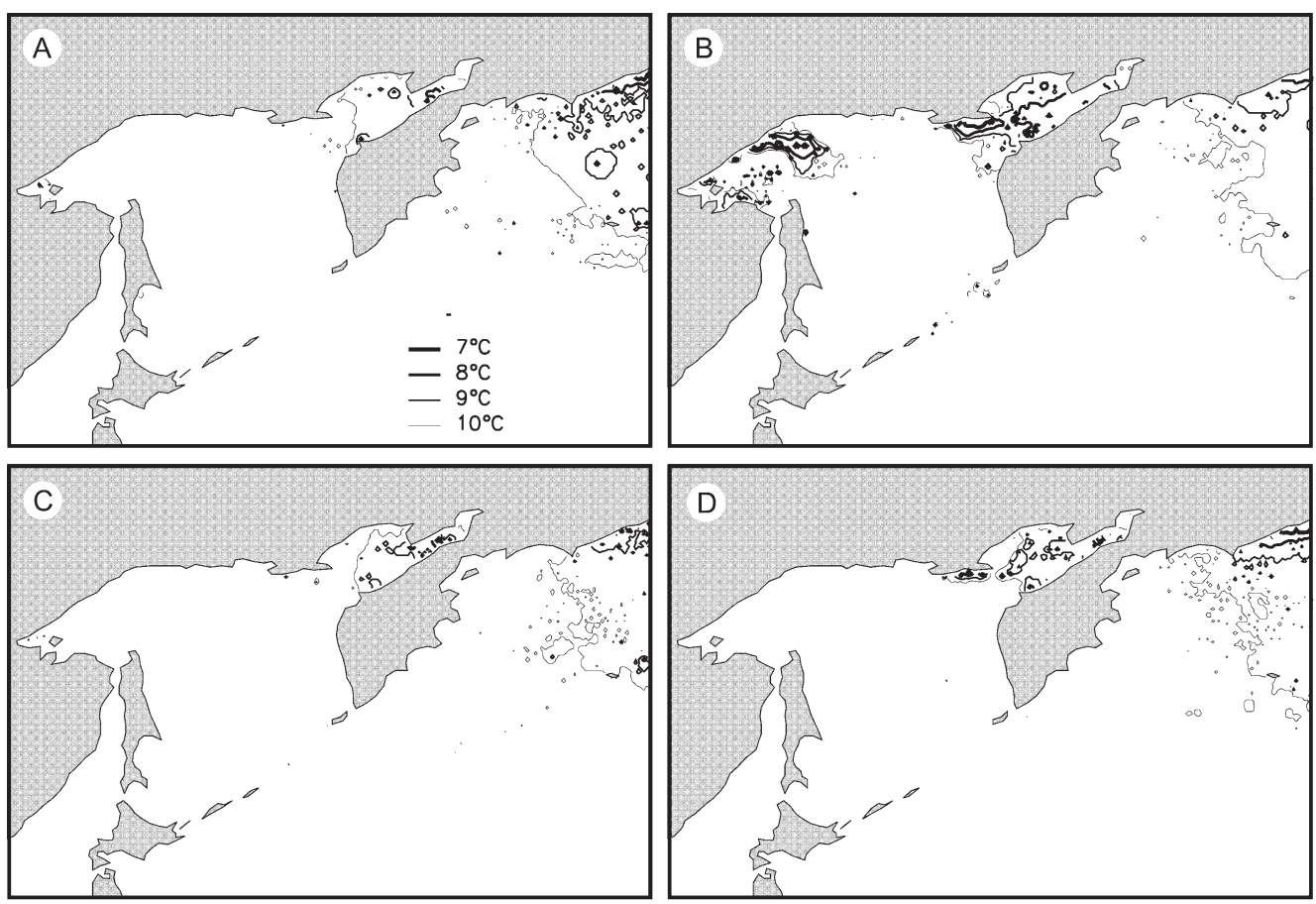

Fig. 14. Positions of the $7,8,9$, and $10^{\circ} \mathrm{C}$ isotherms for the weeks: (A) 2 September (B) 16 September (C) 19 August (D) 26 August

cold water on the data storage tags even if the fish waters around the Kurils, with a relatively shallow thermocline and areas of mixing that can make the came to the surface at night. This further complicates water column practically isothermal, could show up as our interpretations.

Table 5. SST data $\left({ }^{\circ} \mathrm{C}\right)$ around Kuril Islands, August and September 1998. Format: minimum (mean). Minimum temperatures $<8^{\circ} \mathrm{C}$ are in bold

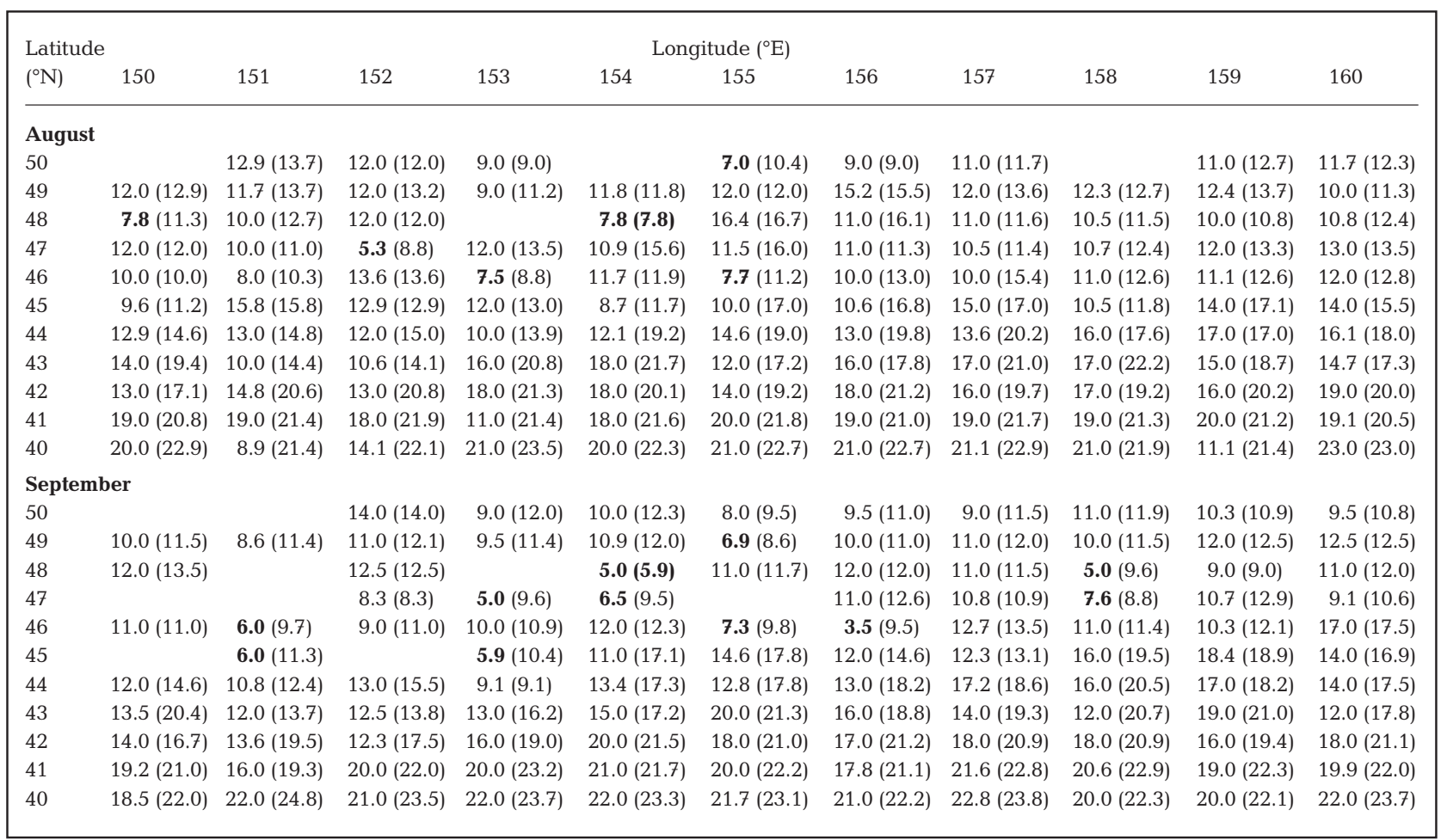


Table 6. Climatological SST $\left({ }^{\circ} \mathrm{C}\right)$ around the Kuril Islands (World Ocean Data Base), August and September 1998. Parentheses, number of observations. Temperatures $<8^{\circ} \mathrm{C}$ are in bold

\begin{tabular}{|c|c|c|c|c|c|c|c|c|c|c|c|}
\hline \multirow{2}{*}{$\begin{array}{l}\text { Latitude } \\
\left({ }^{\circ} \mathrm{N}\right)\end{array}$} & \multicolumn{11}{|c|}{ Longitude $\left({ }^{\circ} \mathrm{E}\right)$} \\
\hline & 150 & 151 & 152 & 153 & 154 & 155 & 156 & 157 & 158 & 159 & 160 \\
\hline \multicolumn{12}{|l|}{ August } \\
\hline $50 \mathrm{~N}$ & $8.9(5)$ & $10.1(5)$ & $9.4(14)$ & $8.2(5)$ & $6.2(13)$ & $7.3(28)$ & $11.4(4)$ & $10.3(6)$ & $10.3(5)$ & $11.1(9)$ & $11.0(7)$ \\
\hline $49 \mathrm{~N}$ & $10.3(6)$ & $11.2(8)$ & $8.9(6)$ & $7.6(7)$ & $4.7(17)$ & $9.0(27)$ & $10.7(20)$ & 10.8 (17) & $10.8(6)$ & $11.2(13)$ & $11.5(10)$ \\
\hline $48 \mathrm{~N}$ & $9.4(15)$ & $8.9(9)$ & $6.6(15)$ & $7.2(18)$ & $8.7(20)$ & $9.8(18)$ & $10.1(12)$ & $11.1(11)$ & $10.6(12)$ & $11.0(8)$ & $12.0(18)$ \\
\hline $47 \mathrm{~N}$ & $7.1(6)$ & $5.5(32)$ & $8.8(35)$ & 10.5 (19) & $9.9(22)$ & $10.6(17)$ & $11.4(17)$ & $10.4(8)$ & $12.0(17)$ & $12.0(14)$ & $12.6(8)$ \\
\hline $46 \mathrm{~N}$ & $8.6(29)$ & $9.3(32)$ & $11.2(38)$ & $11.0(38)$ & $10.7(29)$ & $11.7(28)$ & $11.8(28)$ & 12.7 (17) & $13.2(4)$ & $14.3(8)$ & $13.2(11)$ \\
\hline $45 \mathrm{~N}$ & $13.1(50)$ & $12.2(50)$ & $13.0(37)$ & $12.6(24)$ & $13.1(34)$ & $13.7(27)$ & $13.8(26)$ & $15.1(24)$ & $16.2(11)$ & $15.8(15)$ & 15.9 (10) \\
\hline $44 \mathrm{~N}$ & $16.0(85)$ & $14.5(46)$ & $15.0(40)$ & $15.6(40)$ & $15.8(41)$ & $17.4(25)$ & $17.1(31)$ & $16.5(18)$ & $17.2(24)$ & $16.7(25)$ & $15.3(28)$ \\
\hline $43 \mathrm{~N}$ & $17.0(55)$ & $16.3(46)$ & $17.6(53)$ & $17.4(23)$ & $18.1(23)$ & $17.8(23)$ & $17.4(27)$ & $17.0(26)$ & $17.7(36)$ & $17.3(26)$ & $18.0(18)$ \\
\hline $42 \mathrm{~N}$ & $18.8(79)$ & $20.1(30)$ & $20.2(38)$ & $20.5(22)$ & $19.0(42)$ & $18.1(41)$ & $17.8(41)$ & $19.2(14)$ & 18.7 (15) & $19.1(10)$ & $19.3(12)$ \\
\hline $41 \mathrm{~N}$ & $21.4(49)$ & $21.4(40)$ & $21.2(47)$ & $21.0(49)$ & $19.7(30)$ & $20.5(20)$ & $20.8(22)$ & $22.0(10)$ & 22.9 (9) & $22.7(7)$ & $20.3(14)$ \\
\hline $40 \mathrm{~N}$ & $22.9(107)$ & $22.6(31)$ & $23.2(44)$ & $23.9(55)$ & $22.7(16)$ & 22.7 (15) & $21.8(15)$ & $22.0(10)$ & $21.4(5)$ & $21.5(8)$ & $20.3(6)$ \\
\hline \multicolumn{12}{|c|}{ September } \\
\hline $50 \mathrm{~N}$ & $9.6(6)$ & $10.9(3)$ & $9.7(7)$ & $9.2(7)$ & $7.8(10)$ & $8.7(27)$ & $10.1(34)$ & $11.3(5)$ & $10.5(7)$ & $10.9(10)$ & $11.0(13)$ \\
\hline $49 \mathrm{~N}$ & $9.8(8)$ & $10.2(11)$ & $9.3(8)$ & $6.3(12)$ & $6.1(26)$ & $9.7(18)$ & $11.4(11)$ & 11.7 (15) & $10.5(26)$ & $11.3(14)$ & $11.4(6)$ \\
\hline $48 \mathrm{~N}$ & $10.0(14)$ & $8.5(10)$ & $4.6(207)$ & $9.6(21)$ & $10.5(36)$ & $9.9(27)$ & $9.9(20)$ & $11.3(13)$ & $11.0(12)$ & $9.9(15)$ & $12.1(10)$ \\
\hline $47 \mathrm{~N}$ & $8.6(6)$ & $7.3(41)$ & $9.7(30)$ & $10.0(25)$ & $10.5(28)$ & $10.4(28)$ & $10.9(23)$ & $11.5(12)$ & $11.9(8)$ & $11.8(9)$ & $13.4(7)$ \\
\hline $46 \mathrm{~N}$ & $8.7(32)$ & $10.5(30)$ & $12.0(51)$ & $12.1(29)$ & $12.0(26)$ & $12.2(27)$ & $12.5(10)$ & $12.7(9)$ & $13.1(12)$ & $14.0(8)$ & $14.1(7)$ \\
\hline $45 \mathrm{~N}$ & $13.8(30)$ & $13.3(37)$ & 13.1 (33) & $13.1(34)$ & $13.6(26)$ & $13.8(32)$ & $14.4(11)$ & $14.4(16)$ & $15.2(14)$ & $15.1(16)$ & $15.3(8)$ \\
\hline $44 \mathrm{~N}$ & $14.5(43)$ & 14.7 (218) & $15.2(28)$ & $15.4(41)$ & $17.2(48)$ & $17.1(52)$ & $17.8(35)$ & 15.9 (16) & 16.5 (16) & $16.1(10)$ & $16.2(8)$ \\
\hline $43 \mathrm{~N}$ & $15.8(61)$ & 16.0 (106) & $17.9(67)$ & $18.2(55)$ & $18.2(41)$ & $17.9(50)$ & $17.4(49)$ & $17.5(24)$ & 17.1 (19) & $16.8(18)$ & $16.2(20)$ \\
\hline $42 \mathrm{~N}$ & $18.4(52)$ & $19.1(44)$ & $19.6(52)$ & $19.5(36)$ & $19.3(35)$ & $18.4(37)$ & $18.4(36)$ & $18.3(31)$ & $18.4(20)$ & $17.3(20)$ & $17.7(16)$ \\
\hline $41 \mathrm{~N}$ & 20.7 (33) & $20.6(41)$ & $20.7(37)$ & $20.6(40)$ & $20.3(31)$ & $19.6(46)$ & $19.7(26)$ & 19.3 (15) & 20.1 (19) & $20.2(17)$ & $19.0(17)$ \\
\hline $40 \mathrm{~N}$ & $22.0(38)$ & $21.5(27)$ & $22.4(51)$ & $22.1(48)$ & $21.4(36)$ & $20.7(41)$ & $20.9(27)$ & $20.2(28)$ & $20.9(7)$ & $21.4(9)$ & $20.6(4)$ \\
\hline
\end{tabular}

Although we cannot conclusively prove whether the fish took a direct route along the Kurils or a more northerly route through the Sea of Okhotsk, the temperature data does argue against a southerly route. There is virtually no evidence of upwelling or cold surface water south of $45^{\circ} \mathrm{N}$. Furthermore, a southward migration would also be against the major currents in the region, i.e. the Subarctic and Kuroshio currents. The Kamchatka and Oyashio currents would assist direct migration along the Kurils; a westward route, followed by movement through the Sea of Okhotsk, would be assisted by the Kamchatka current and Okhotsk gyre (Fig. 1A).

The complex diving patterns displayed by chum salmon throughout and especially near the end of their homing migration have stimulated interest in the role of reproductive physiology in diel diving. Deepwater diving by salmon is thought to increase energetic efficiency during the onset of reproductive development (Ueno 1992, Radchenko et al. 1998). As seen with tag 271, the diving was so systematic that a non-physiological explanation is difficult to conceive. An alternative hypothesis is that the dives during the day may improve the efficiency of migration. During their long migrations in the northeastern Pacific, northern elephant seals Mirounga angustirostris use a variety of diving behaviors, some of which are clearly adapted to transit, considering the angles of ascent and decent used by the animal (Le Boeuf et al. 1992). If this is also the case in chum salmon, the fact that diving behavior only occurs during daylight hours supports our contention that most directed movement is occurring during the day.

Acknowledgements. We thank K. Y. Aydin and G. Anma for their assistance, and the late H. R. Carlson for his support of high seas salmon research. Funding for the application of the tags and tag rewards was provided by the Ocean Carrying Capacity program of the Auke Bay Laboratory, Alaska Fisheries Science Center, NMFS (University of Washington portion under NOAA contract 50ABNF70003).

\section{LITERATURE CITED}

Berthold P, Helbig AJ, Mohr G, Querner U (1992) Rapid microevolution of migratory behavior in a wild bird species. Nature 360:668-670

Dat CG, Leblond PH, Thomson KA, Ingraham WJ (1995) Computer simulations of homeward migrating Fraser River sockeye salmon - is compass orientation a sufficient direction finding mechanism in the Northeast Pacific Ocean. Fish Oceanogr 4:209-216

Deutschlander ME, Borland SC, Phillips JB (1999a) Extraocular magnetic compass in newts. Nature 400:324-325

Deutschlander ME, Phillips JB, Borland SC (1999b) The case for light-dependent magnetic orientation in animals. J Exp Biol 202:891-908 
Diebel CE, Proksch R, Green CR, Neilson P, Walker MM (2000) Magnetite defines a vertebrate magnetoreceptor. Nature 406:299-302

Dittman AH, Quinn TP (1996) Homing in Pacific salmon: mechanisms and ecological basis. J Exp Biol 199:83-91

Flamarique IN, Hawryshyn CW (1993) Spectral characteristics of salmonid migratory routes from Southern Vancouver Island (British Columbia). Can J Fish Aquat Sci 50: $1706-1716$

Gould JL (1998) Sensory Bases of Navigation. Curr Biol 8: R731-R738

Hansen LP, Quinn TP (1998) The marine phase of the Atlantic salmon (Salmo salar) life cycle, with comparisons to Pacific salmon. Can J Fish Aquat Sci 55, Suppl 1:104-118

Hansen LP, Jonsson N, Jonsson B (1993) Oceanic migration in homing Atlantic salmon. Anim Behav 45:927-941

Hasler AD (1971) Orientation and fish migration. In: Hoar WS, Randall DJ (eds) Fish physiology, Vol VI, Environmental relations and behavior. Academic Press, New York, p 429-510

Haugh CV, Walker MM (1998) Magnetic Discrimination Learning in Rainbow Trout (Oncorhynchus mykiss). J Navigation 51:35-45

Hawryshyn CW, Arnold MG, Bowering E, Cole RL (1990) Spatial orientation of rainbow trout to plan polarized light: the ontogeny of e-vector discrimination and spectral sensitivity characteristics. J Comp Physiol 166:565-574

Hiramatsu K, Ishida Y (1989) Random movement and orientation in pink salmon (Oncorhynchus gorbuscha) migrations. Can J Fish Aquat Sci 46:1062-1066

Ishida Y, Yano A, Ban M, Ogura M (1998) Vertical movement of chum salmon, Oncorhychus keta, in the western North Pacific Ocean as determined by a depth-recording archival tag. National Research Institute of Far Sea Fisheries, Salmon Report Series 45, Shimizu, Japan, p 199-210

Jamon M (1990) A reassessment of the random hypothesis in the ocean migration of Pacific salmon. J Theor Biol 143: $197-213$

Kono T, Kawasaki Y (1997) Modification of the western subarctic water by exchange with the Okhotsk Sea. Deep-Sea Res Part 1 Oceanogr Res Pap 44:689-711

Koo TSY (ed) (1962) Age designation in salmon. In: Publications in Fisheries, New Series; Vol 1, Studies of Alaska Red Salmon. University Washington Press, Seattle, WA, p 37-48

Le Boeuf BJ, Naito Y, Asaga T, Crocker D, Costa DP (1992) Swim speed in a female northern elephant seal: metabolic and foraging implications. Can J Zool 70:786-795

Leggett WC (1977) The ecology of fish migrations. Ann Rev Ecol Syst 8:285-308

Levitus S, Boyer TP, Conkright ME, O'Brien T, Antonov J, Stephens C, Stathoplos L, Johnson D, Gelfeld R (1998) NOAA Atlas NESDIS 18, World Ocean Database 1998: Vol. 1: Introduction, US Government Printing Office, Washington DC

Lohmann KJ, Lohmann CMF (1998) Sea turtle navigation and the detection of geomagnetic field features. J Navigation 51:10-22

Merrill RT, McElhinny, McFadden PL (1996) The magnetic field of the earth. Academic Press, Boston

Moore A, Freake AM, Thomas IM (1990) Magnetic particles in the lateral line of the Atlantic salmon (Salmo salar L.). Phil Trans R Soc Lond B Biol Sci 329:11-15

Nagasawa K, Ueno Y, Sakai J, Mori, J (1998) Autumn distribution of epipelagic fish and squids in the Okhotsk Sea and western North Pacific Ocean off the Kuril Islands and southeast Hokkaido. Bull Natl Res Inst Far Seas Fish 35: $113-130$
Nordtug T, Berg OK, Melo TB (1994) Directional light transmission in the pineal window of Atlantic salmon (Salmo salar L.) may be used for solar orientation. J Exp Zool 269: 403-412

Ogura M, Ishida Y (1992) Swimming behavior of coho salmon, Oncorhynchus kisutch, in the open sea as determined by ultrasonic telemetry. Can J Fish Aquat Sci 49:453-457

Ogura M, Ishida Y (1995) Homing behavior and vertical movements of four species of Pacific salmon (Oncorhynchus spp.) in the central Bering Sea. Can J Fish Aquat Sci 52:532-540

Ogura M, Kato M, Arai N, Sasada T, Sakaki Y (1992) Magnetic particles in chum salmon (Onchorhynchus keta): extraction and transmission electron microscopy. Can J Zool 70:874-877

Quinn TP (1980) Evidence for celestial and magnetic compass orientation in lake migrating sockeye salmon fry. J Comp Physiol 137:243-248

Quinn TP (1991) Models of Pacific salmon orientation and navigation on the open ocean. J Theor Biol 150:539-545

Quinn TP, Brannon EL (1982) The use of celestial and magnetic cues by orienting sockeye salmon smolts. J Comp Physiol A Sens Neural Behav Physiol 147A: 547-552

Quinn TP, Groot C (1984) Pacific salmon (Oncorhynchus) migrations: orientation versus random movement. Can J Fish Aquat Sci 41:1319-1324

Quinn TP, Terhart BA, Groot C (1989) Migratory orientation and vertical movements of homing adult sockeye salmon, Oncorhynchus Nerka, in coastal waters. Anim Behav 37: 587-599

Radchenko VI, Glebov II (1998) On vertical distribution of Pacific salmon in the Bering Sea, collected by trawling data. J Ichthyol 38:603-608

Reynolds RW (1988) A real-time global sea surface temperature analysis. J Climate 1:75-86

Reynolds RW, Marsico DC (1993) An improved real-time global sea surface temperature analysis. J Climate 6: $114-119$

Reynolds RW, Smith TM (1994) Improved global sea surface temperature analyses using optimum interpolation. J Climate 7:929-948

Royce WF, Smith LS, Hartt AC (1968) Models of oceanic migrations of Pacific salmon and comments on guidance mechanisms. Fish Bull 66:441-462

Ruggerone GT, Quinn TP, McGregor IA, Wilkinson TD (1990) Horizontal and vertical movements of adult steelhead trout, Oncorhynchus mykiss, in the Dean and Fisher channels, British Columbia. Can J Fish Aquat Sci 47:1963-1969

Saila SB, Shappy RA (1963) Random movement and orientation in salmon migration. J Cons Int Explor Mer 28: 153-166

Shuntov VP (1989) Distribution of juvenile Pacific salmon, Oncorhynchus, in the Okhotsk Sea and adjoining Pacific waters. J Ichthyol 29:155-164

Shuntov VP, Radchenko VI, Lapko VV, Poltev YuN (1993) Distribution of Salmon in Sakhalin-Kuril Waters During Their Anadromous Migration. J Ichthyol 33:63-77

Smith E, Vazquez J, Tran A, Sumagaysay R (1996) Satellitederived sea surface temperature data available from the NOAA/NASA Pathfinder program http://www.agu. org/eos_elec/95274e.html ${ }^{\odot} 1996$ American Geophysical Union

Stepanov AS, Churmasoc AV, Cherkashin SA (1979) Migration direction finding by chum salmon according to the sun. Sov J Mar Biol 5:92-99

Thomson KA, Ingraham WJ, Healey MC, Leblond PH, Groot C, Healey CG (1992) The influence of ocean currents on 
latitude of landfall and migration speed of sockeye salmon returning to the Fraser River. Fish Oceanogr 1:163-179

Thomson KA, Ingraham WJ, Healey MC, Leblond PH, Groot C, Healey CG (1994) Computer simulations of the influence of ocean currents on Fraser River sockeye salmon (Oncorhynchus nerka) return times. Can J Fish Aquat Sci 51:441-449

Ueno Y (1992) Deepwater migrations of chum salmon (Oncorhynchus keta) along the Pacific coast of northern Japan. Can J Fish Aquat Sci 49:2307-2312

Wada K, Ueno Y (1999) Homing behavior of chum salmon determined by an archival tag (NPAFC Doc. 425) Hokkaido National Fisheries Research Institute, Hokkaido

Walker MM, Diebel CE, Haugh CV, Pankhurst PM, Montgomery JC, Green CR (1997) Structure and function of the vertebrate magnetic sense. Nature 390:371-376

Walker MM, Quinn TP, Kirschvink JL, Groot C (1988) Produc-

Editorial responsibility: Kenneth Sherman (Contributing

Editor), Narragansett, Rhode Island, USA tion of single-domain magnetite throughout life by sockeye salmon, Oncorhychus nerka. J Exp Biol 140:51-63

Walker RV, Myers KW, Davis ND, Aydin KY, Friedland KD, Carlson HR, Boehlert GW, Urawa S, Ueno Y, Anma G (2000) Diurnal variation in thermal environment experienced by salmonids in the North Pacific as indicated by data storage tags. Fish Oceanogr 9:171-186

Wiltschko W, Wiltschko R (1996) Magnetic orientation in birds. J Exp Biol 199:29-38

Woodruff SD, Diaz HF, Elms JD, Worley SJ (1998) COADS Release 2 data and metadata enhancements for improvements of marine surface flux fields. Phys Chem Earth 23: $517-527$

Yano A, Ogura M, Sato A, Sakaki Y, Shimizu Y, Baba N, Nagasawa K (1997) Effect of modified magnetic field on the ocean migration of maturing chum salmon, Oncorhynchus keta. Mar Biol 129:523-530

Submitted: July 17, 2000; Accepted: October 17, 2000 Proofs received from author(s): June 25, 2001 